\title{
NBER WORKING PAPER SERIES \\ SOURCES OF INACTION IN HOUSEHOLD FINANCE: \\ EVIDENCE FROM THE DANISH MORTGAGE MARKET
}

\author{
Steffen Andersen \\ John Y. Campbell \\ Kasper Meisner Nielsen \\ Tarun Ramadorai \\ Working Paper 21386 \\ http://www.nber.org/papers/w21386 \\ NATIONAL BUREAU OF ECONOMIC RESEARCH \\ 1050 Massachusetts Avenue \\ Cambridge, MA 02138 \\ July 2015, Revised July 2019
}

An earlier version of this paper was circulated under the title "Inattention and Inertia in Household Finance: Evidence from the Danish Mortgage Market." We thank the Sloan Foundation for financial support. We are grateful to the Association of Danish Mortgage Banks (ADMB) for providing data and facilitating dialogue with the individual mortgage banks, and to senior economists Bettina Sand and Kaare Christensen at the ADMB for providing us with valuable institutional details. We thank Sumit Agarwal, Joao Cocco, John Driscoll, Xavier Gabaix, Samuli Knüpfer, David Laibson, Tomasz Piskorski, Tano Santos, Antoinette Schoar, Amit Seru, Susan Woodward, Vincent Yao, and seminar participants at the Board of Governors of the Federal Reserve/GFLEC Financial Literacy Seminar at George Washington University, the NBER Summer Institute Household Finance Meeting, the Riksbank-EABCN Conference on Inequality and Macroeconomics, the American Economic Association 2015 Meeting, the Real Estate Seminar at UC Berkeley, the Federal Reserve Bank of New York, Copenhagen Business School, Columbia Business School, the May 2015 Mortgage Contract Design Conference, the NUS-IRES Real Estate Symposium, Chicago Booth, the European Finance Association 2015 Meeting, the FIRS 2016 Meeting, the Imperial College London-FCA Conference on Mortgage Markets, Cass Business School, the Banca d'Italia, Wharton, Boston College, Stanford, the 2017 Conference on the Econometrics of Financial Markets, Bocconi, and Lugano for many useful comments, and Josh Abel and Federica Zeni for excellent and dedicated research assistance. The views expressed herein are those of the authors and do not necessarily reflect the views of the National Bureau of Economic Research.

At least one co-author has disclosed a financial relationship of potential relevance for this research. Further information is available online at http://www.nber.org/papers/w21386.ack

NBER working papers are circulated for discussion and comment purposes. They have not been peer-reviewed or been subject to the review by the NBER Board of Directors that accompanies official NBER publications.

(C) 2015 by Steffen Andersen, John Y. Campbell, Kasper Meisner Nielsen, and Tarun Ramadorai. All rights reserved. Short sections of text, not to exceed two paragraphs, may be quoted without explicit permission provided that full credit, including () notice, is given to the source. 
Sources of Inaction in Household Finance: Evidence from the Danish Mortgage Market Steffen Andersen, John Y. Campbell, Kasper Meisner Nielsen, and Tarun Ramadorai NBER Working Paper No. 21386

July 2015, Revised July 2019

JEL No. G11,G21

\begin{abstract}
$\underline{\text { ABSTRACT }}$ channel of monetary policy transmission.

$\begin{array}{ll}\begin{array}{l}\text { Steffen Andersen } \\ \text { Department of Finance } \\ \text { Copenhagen Business School }\end{array} & \begin{array}{l}\text { Kasper Meisner Nielsen } \\ \text { Hong Kong University } \\ \text { of Science and Technology } \\ \text { Porcelænshaven 16A, 1 } \\ \text { DK-2000 Frederiksberg } \\ \text { Denmark } \\ \text { san.fi@cbs.dk }\end{array} \\ \begin{array}{l}\text { Hong Kong } \\ \text { nielsen@ @ ust.hk }\end{array} \\ \text { John Y. Campbell } & \text { Tarun Ramadorai } \\ \text { Morton L. and Carole S. } & \text { Imperial College London } \\ \text { Olshan Professor of Economics } & \text { London SW7 2AZ } \\ \text { Department of Economics } & \text { United Kingdom } \\ \text { Harvard University } & \text { t.ramadorai@imperial.ac.uk } \\ \text { Littauer Center 213 } & \\ \text { Cambridge, MA 02138 } & \\ \text { and NBER } & \\ \text { john_campbell@ harvard.edu } & \end{array}$
\end{abstract}

We build an empirical model to decompose delays in mortgage refinancing into time-dependent inaction (a low probability of responding to a refinancing incentive in a given quarter) and statedependent inaction (a psychological addition to the financial cost of refinancing). We estimate the model on high-quality administrative panel data from Denmark, where mortgage refinancing without cash-out is unconstrained. Middle-aged and wealthy households exhibit state-dependent inaction; but older, poorer, and less-educated households exhibit strong time-dependent inaction and thereby achieve lower savings. We use the model to understand frictions in the mortgage

A online appendix is available at http://www.nber.org/data-appendix/w21386 


\section{Introduction}

A pervasive finding in studies of household financial decision-making is that households respond slowly to changing financial incentives. Inaction is common, even in circumstances where market conditions are changing continuously, and actions often occur long after the incentive to take them has first arisen. Well known examples include participation, saving, and asset allocation decisions in retirement savings plans, and portfolio rebalancing in response to fluctuations in risky asset prices. ${ }^{2}$ In this paper we study mortgage refinancing - a particularly important decision given the size of mortgages relative to household budgets - with a view towards shedding light on the underlying structural determinants of inaction. We do so in Denmark, an environment uniquely suited to analyzing these questions, using a large panel of high-quality administrative data.

One standard explanation for inaction is that there are fixed costs of taking action, so that households do so only when the benefits are sufficiently large. $(S, s)$ models of optimal inaction in the presence of fixed costs have been a staple of the economics literature since the 1950s. They have been used to model many different decisions, including those by firms to change their prices (Caplin and Spulber 1987, Caballero and Engel 1991, Caplin and Leahy 1991) and decisions by households to switch health insurance plans (Handel 2013). These models are sometimes called "state-dependent" because financial incentives determine whether or not an action is taken.

In the case of mortgage refinancing, monetary fixed costs justify an inaction range until the interest rate saving reaches an optimal threshold that triggers refinancing. Inaction beyond this point can be explained by psychological costs of refinancing that shift the threshold, widening the inaction range. These psychological costs could reflect the value of time spent executing a refinancing, possibly augmented by behavioral present bias that makes households reluctant to incur current time costs for the sake of future benefits (Laibson 1997, O’Donoghue and Rabin 1999).

As an initial step to evaluate this state-dependent approach, we calculate an optimal refinancing

\footnotetext{
${ }^{2}$ See for example Agnew, Balduzzi, and Sunden (2003), Choi, Laibson, Madrian, and Metrick (2002, 2004), and Madrian and Shea (2001) on retirement savings plans, and Anagol, Balasubramaniam, and Ramadorai (2018), Bilias, Georgarakos, and Haliassos (2010), Brunnermeier and Nagel (2008), and Calvet, Campbell, and Sodini (2009a) on portfolio rebalancing.
} 
threshold for each household-quarter in our data, using a model recently proposed by Agarwal, Driscoll, and Laibson (ADL 2013). We show that households commonly fail to refinance despite having potential interest rate savings greater than the ADL threshold. This finding of pervasive slow refinancing is consistent with results reported by Agarwal, Rosen, and Yao (2016) and Keys, Pope, and Pope (2016) in US data. ${ }^{3}$

Is this evidence consistent with a purely state-dependent model of household refinancing inaction? In a static setting where each household is observed only once, unobserved psychological refinancing costs can explain any pattern of refinancing behavior. Since refinancing depends on the distribution of thresholds, this distribution can be backed out directly from the data, but the model implies no further restrictions. In a dynamic setting where households are observed repeatedly, however, a state-dependent model of inaction with fixed, unobserved refinancing costs does restrict behavior. The model predicts that no household will ever refinance for the first time at an incentive (an interest saving relative to its household-specific threshold) that is lower than one it faced at an earlier period; and after a first-time refinancing, a household will never refinance at a different incentive, or fail to refinance at a higher incentive, than the one that triggered the initial refinancing. These restrictions are far from satisfied by household behavior in our panel data.

To relax these restrictions, one needs a model in which household behavior varies over time. Standard discrete-choice models, such as the logit and probit models, specify that an action is taken if a random shock is large enough that a linear combination of household characteristics and the shock exceeds a fixed threshold. If a new shock is drawn for each household in each period, then the decisions of a given household need not be tightly related across different periods. Models of this sort can be extremely flexible if the distribution of shocks is allowed to vary across households and over time; but for this very reason, they can sometimes be difficult to interpret in terms of a plausible economic model of household behavior.

An alternative explanation for inaction is that households monitor their financial circumstances

\footnotetext{
${ }^{3}$ We verify that our results are not sensitive to the parameterization of the ADL optimal refinancing model or to our decision to use the ADL model as the rational refinancing benchmark. We also compare the ADL threshold to the recommendations of financial advisors and to the decisions of prompt Danish refinancers.
} 
intermittently rather than continuously. Empirical models of this phenomenon generally specify time intervals of constant duration during which households take no action, or a constant probability of taking action in any one period, as in the well-known Taylor (1980) and Calvo (1983) models of firms' price-setting decisions. Importantly, in these models the length of inactive periods is unaffected by the financial incentives to act; hence, these are known as "time-dependent" models. Time-dependence can be microfounded if households have information-gathering costs - fixed costs of gathering information and evaluating the incentives to act (Duffie and Sun 1990, Gabaix and Laibson 2002, Reis 2006a,b, Abel, Eberly, and Panageas 2007). ${ }^{4}$

The time-dependent specification is simple and tractable. However, a pure time-dependent model cannot explain why refinancing responds to the interest saving; and even a time-dependent model with a refinancing threshold determined by monetary fixed costs implies, counterfactually, that the interest saving no longer affects refinancing behavior once it exceeds that threshold.

We therefore estimate a new empirical model of mortgage refinancing that nests state-dependent and time-dependent models of inaction. Our model incorporates both a psychological refinancing cost that widens the inaction range, as in a state-dependent model, and a constant probability of considering a refinancing in any period, as in a time-dependent model. In addition, we allow random shocks to affect household choice in each period, but to discipline this flexibility, we specify that the distribution of these shocks is constant across households and over time. In our baseline model we assume that the psychological refinancing cost is the same for all households with the same observable demographic characteristics, but in an extension of the model we allow for unobserved heterogeneity in psychological refinancing costs.

The resulting model can separately identify state-dependent and time-dependent sources of inaction, even though we observe neither households' observations of data nor their psychological costs of taking action. To understand how this is possible, first consider a baseline model in which psychological refinancing costs depend solely on observed household characteristics. In this case,

\footnotetext{
${ }^{4}$ An alternative to a fixed cost of gathering information is a cost that increases in the content of the information, as in the "rational inattention" models of Sims (2003), Moscarini (2004), Woodford (2009), and Matějka and McKay (2015). Veldkamp (2011) and Caplin (2016) survey this literature.
} 
state-dependent and time-dependent sources of inaction have different effects on household behavior in a single cross-section of refinancing incentives. State-dependent inaction reduces refinancing at incentives below the (household-characteristics specific) threshold, but it has no effect on refinancing at sufficiently high incentives. However, time-dependent inaction lowers the probability that households refinance at all levels of incentives.

Now consider a model that also allows unobserved heterogeneity in psychological refinancing costs. State-dependent and time-dependent inaction can no longer be separately identified in a single cross-section, but they can when household behavior is observed over time. A household that monitors mortgage markets continuously but has a large unobserved psychological refinancing cost will rarely refinance at a low incentive, but will reliably do so at a high incentive. A household with a low probability to even consider refinancing, on the other hand, will have a low refinancing propensity that is relatively insensitive to the level of incentives it faces. A large one-time decline in interest rates will trigger a rapid refinancing response from households of the first type, but a delayed response from households of the second type.

Estimating the model on the Danish data, we document how demographic characteristics alter the prevalence of state- and time-dependent inaction manifested in slow mortgage refinancing. We find that psychological refinancing costs are hump-shaped in age and generally increasing in measures of socioeconomic status, with a particularly large effect on financially wealthy households. This pattern is consistent with the idea that such costs reflect, at least in part, the unmeasured value of time spent on mortgage refinancing. By contrast, older households with lower education, income, housing wealth, and financial wealth are less likely to consider refinancing, regardless of the financial incentive to do so; their slow refinancing is well described by a time-dependent model. Overall, we find that state-dependent and time-dependent inaction affect different types of households.

These findings can guide further work modeling household financial behavior. The fact that older, less educated, and poorer households follow time-dependent refinancing rules suggests that for them, information-gathering costs are important. Middle-aged households with higher income and wealth, however, behave as if their time is valuable and they will allocate it only to activities 
with a high payoff. Household finance models should accommodate heterogeneity of this sort.

In addition to providing insights into the sources of inaction in household finance, our work has implications for the transmission of monetary policy through the mortgage refinancing channel. Consider for example a one-time decline in interest rates to a lower level that then remains unchanged. In a model with time-dependent inaction, the interest rate decline has delayed effects on refinancing, because some households react only with a lag. Over time, however, in a pure time-dependent model, all households with refinancing incentives above the optimal threshold do refinance. In contrast, in a model with pure state-dependent inaction, the interest rate decline generates an instantaneous refinancing wave by the subset of households whose refinancing incentives move above the higher threshold defined by their psychological refinancing costs. However there is no further refinancing predicted by the pure state-dependent model after the initial period. We show how these predictions play out in the Danish data using a series of counterfactual, partial equilibrium simulations from our model.

A note on the data is in order. Our empirical work analyzes a comprehensive administrative dataset on refinancing decisions in Denmark between 2009 and 2017. The Danish mortgage system is ideal for our purpose because, while it is similar to the US system in that long-term fixed-rate mortgages are common and can be refinanced without penalties related to the level of interest rates, it differs in two ways that facilitate our analysis.

First, Danish households are free to refinance their mortgages whenever they choose to do so, even if their home equity is negative or their credit standing has deteriorated, provided that they do not "cash out" by extracting home equity. Danish borrowers can add the fixed costs of refinancing to their mortgage balance without triggering the cash-out restriction, so refinancing does not require liquid financial assets and is not affected by borrowing constraints. In the US mortgage system, by contrast, households are constrained from refinancing when they have negative home equity or impaired credit scores, and it is difficult to accurately measure these constraints. These features of the Danish mortgage system allow us to study household refinancing behavior without having to control for the additional constraints that restrict refinancing in the US. 
Second, the Danish statistical office provides us with accurate administrative data on household demographic and financial characteristics at each point in time, for all mortgage borrowers including both refinancers and non-refinancers. This allows us to measure the prevalence of time-and statedependent slow refinancing across demographic groups. This again stands in contrast with the US system, where it is challenging to measure borrower characteristics continuously. These are reported only at the time of a mortgage application in the US, through the form required by the Home Mortgage Disclosure Act (HMDA), and hence one cannot directly compare the characteristics of refinancers and non-refinancers at a point in time using these data.

\subsection{Related literature}

Almost all previous research on mortgage refinancing has studied US data. Slow mortgage prepayment and risk created by random time-variation in prepayment rates were the main preoccupations of a large literature on the pricing and hedging of US mortgage-backed securities in the years before the global financial crisis of the late 2000s. ${ }^{5} \quad$ Since the financial crisis, there has been interest in the extent to which slow refinancing - caused either by household inaction or by refinancing barriers - has reduced the effectiveness of expansionary US monetary policy (Auclert 2016, Agarwal et al. 2015, Beraja et al. 2017, Di Maggio et al. 2016). Two exceptions to the US focus of the refinancing literature are Miles (2004) and Bajo and Barbi (2016), which study the UK and Italy respectively. Badarinza et al (2016) advocate more generally for an international comparative approach to household finance.

Within the US refinancing literature, many papers have tried to overcome the limited data available on refinancing constraints and the characteristics of non-refinancing households. Agarwal, Rosen, and Yao (2016) and Keys, Pope, and Pope (2016) use a number of ingenious techniques to handle these problems, combining available data to impute household variables that they cannot observe such as current creditworthiness and demographic characteristics. Keys, Pope, and Pope (2016) and Johnson, Meier, and Toubia (2015) also study pre-approved refinancing offers that

\footnotetext{
${ }^{5}$ See for example Schwartz and Torous (1989), McConnell and Singh (1994), Stanton (1995), Deng, Quigley, and Van Order (2000), Bennett, Peach, and Peristiani (2001), and Gabaix, Krishnamurthy, and Vigneron (2007).
} 
eliminate refinancing constraints, but these are relatively infrequent and thus samples are small. ${ }^{6}$ In the aftermath of the global financial crisis, the US government tried to relax refinancing constraints through the Home Affordable Refinance Program (HARP), but the effectiveness of this program remains an outstanding research question (Agarwal et al. 2015, Tracy and Wright 2012, Zandi and deRitis 2011, Zhu 2012).

Our work is also related to a broader literature on the difficulties households have in managing their mortgage borrowing. Campbell and Cocco (2003, 2015) specify models of optimal choice between FRMs and ARMs, and optimal prepayment and default decisions, showing how challenging it is to make these decisions correctly. Chen, Michaux, and Roussanov (2013) similarly study decisions to extract home equity through cash-out refinancing, while Khandani, Lo, and Merton (2013) and Bhutta and Keys (2016) argue that households used cash-out refinancing to borrow too aggressively during the housing boom of the early 2000s. Bucks and Pence (2008) provide direct survey evidence that ARM borrowers are unaware of the exact terms of their mortgages, specifically the range of possible variation in their mortgage rates, and Woodward and Hall $(2010,2012)$ and Bhutta, Fuster, and Hizmo (2018) argue that borrowers pay excessive mortgage fees because they do not shop for lower-cost mortgages.

A recent literature has explored ways to combine time-dependent and state-dependent inaction. Nakamura and Steinsson (2010) estimate a "CalvoPlus" model of firms' price-setting which incorporates both elements. Some recent theoretical papers have characterized optimal behavior when households have both action costs and information-gathering costs (Alvarez, Lippi, and Paciello 2011, Abel, Eberly, and Panageas 2013). Optimal policies are complicated in this situation, and typically involve both discrete periods of inactivity and inaction ranges. The two types of costs have interacting effects, because the benefit of gathering information is reduced when the action that would exploit the information is itself costly; and the optimal threshold for taking action in a particular period, having gathered information, may be lower when an agent knows that considering action in the future will incur a new information-gathering cost. Structural estimation of such

\footnotetext{
${ }^{6}$ Earlier attempts to control for constraints and measure refinancer and non-refinancer characteristics include Archer, Ling, and McGill (1996), Campbell (2006), Caplin, Freeman, and Tracy (1997), LaCour-Little (1999), and Schwartz (2006).
} 
models is challenging, although Alvarez, Guiso, and Lippi (2012) make some progress using data in which households' observations of financial conditions are directly measured.

The organization of our paper is as follows. Section 2 explains the Danish mortgage system and household data. Section 3 summarizes the deviations of Danish household behavior from a benchmark model of rational refinancing. Section 4 sets up our econometric model with both time-dependent and state-dependent inaction, estimates the model empirically, and interprets the cross-sectional patterns of coefficients. This section also assesses the robustness of our results to the mortgage sample and the specification of the optimal refinancing threshold, and uses our model to ask how plausible modifications to the mortgage system might affect refinancing behavior. Section 5 concludes. An online appendix (Andersen, Campbell, Nielsen, and Ramadorai 2019) provides many supporting details.

\section{The Danish Mortgage System and Household Data}

\subsection{The Danish mortgage system}

The Danish mortgage system is similar to the US system in offering long-term fixed-rate mortgages without prepayment penalties, but it has a number of design features that differ from the US model (Campbell 2013, Gyntelberg et al. 2012, Lea 2011). In this section we briefly review the funding of Danish mortgages and the rules governing refinancing. Online Appendix A provides some additional details on the Danish system.

\section{A. Mortgage funding}

Danish mortgages, like those in some other continental European countries, are funded using covered bonds: obligations of mortgage lenders that are collateralized by pools of mortgages. These bonds are currently issued by seven mortgage banks, who operate in a highly competitive market and charge very similar mortgage rates and administration fees. While mortgages on various types 
of property are eligible as collateral for mortgage bonds, mortgages on residential property dominate most collateral pools.

Danish mortgage banks act as intermediaries between investors and borrowers. Investors buy mortgage bonds which are issued by the mortgage banks and backed by a pool of mortgages, while borrowers take out mortgages from the banks. All lending is secured, and once banks initially screen borrowers, they have no further influence on mortgage rates, which are entirely determined by the market. Borrowers pay the coupons on the mortgage bonds, as well as a fee to the mortgage bank to compensate for administrative costs and the bank's credit exposure. This fee is roughly 70 basis points on average, and depends on the loan-to-value (LTV) ratio on the mortgage, but is otherwise independent of household characteristics. Borrowers' retail banks work with the mortgage banks to arrange mortgage issuance and settle monthly payments.

Under this system mortgage payments, including prepayments, flow directly to covered bond investors. As a result, prepayments do not affect the cash flows received by mortgage banks, except through their effect on fee receipts on account of contract termination. If a borrower defaults, however, the mortgage bank must replace the defaulted mortgage in the pool that backs the mortgage bond. This ensures that investors are unaffected by defaults in their borrower pool so long as the bank remains solvent. In effect, bond investors bear interest rate and prepayment risk, while mortgage banks retain credit risk. ${ }^{7}$

Traditionally the Danish system has been dominated by fixed-rate mortgages, although adjustablerate mortgages have become more popular in the last 15 years. Badarinza, Campbell, and Ramadorai (2016) report that the average share of adjustable-rate mortgages in Denmark was $45 \%$ in the period 2003-13, with a standard deviation of $13 \%$. At the beginning of our sample period in 2009, the adjustable-rate mortgage share was roughly $40 \%$.

\section{B. Refinancing}

Fixed-rate mortgage borrowers in Denmark have the right to prepay their mortgages without

\footnotetext{
${ }^{7}$ Banks' credit risk exposure is reduced by the fact that Danish mortgages, like those in other European countries and in some US states, have personal recourse against borrowers.
} 
incurring penalties. As in the US, refinancing fees increase with mortgage size but do not vary with the level of interest rates. However the prepayment system in Denmark also differs from the US system in several important respects.

An important feature is that the Danish mortgage system imposes minimal barriers to any refinancing that does not "cash out" (in a sense to be made more precise below). Danish borrowers can refinance their mortgages to reduce their interest rate and/or extend their loan maturity, without cashing out, even if their homes have declined in value (i.e., even when they have negative home equity). Related to this, refinancing without cashing out does not require a review of the borrower's credit quality. $^{8}$ Moreover, refinancing costs do not need to be paid up front, but can be added to mortgage principal as part of a refinancing, without being counted as a cash-out. These features of the system imply that all mortgage borrowers, including those whose credit quality has deteriorated, can benefit from a decline in interest rates, even in a weak economy with declining house prices and consumer deleveraging.

Mortgage banks have incentives to refinance mortgages in this way because, as previously mentioned, they do not receive mortgage cash flows but do bear credit risk; and refinancing to take advantage of lower interest rates reduces the risk of default by lowering mortgage payments and relieving household budgets. Retail banks, similarly, have incentives to advise their customers to refinance because they earn fees for arranging the transaction. This structure reduces refinancing frictions that have been identified in the US market arising from imperfect competition in mortgage origination (Agarwal et al. 2015).

The mechanics of refinancing in Denmark are as follows. A mortgage bank, working on behalf of a borrower, repurchases mortgage bonds corresponding to the mortgage debt, and delivers them to the mortgage lender. This repurchase can be done either at market value or at face value. It is advantageous to repurchase bonds at market value if interest rates have risen since mortgage

\footnotetext{
${ }^{8}$ Denmark does not have a system of continuous credit scores like the widely used FICO scores in the US. Instead, there is what amounts to a zero/one scoring system that can be used to label an individual as a delinquent borrower ("dårlig betaler") who has unpaid debt outstanding. A delinquent borrower would be unlikely to obtain a mortgage, but a borrower with an existing mortgage can refinance, without cashing out, even if he or she has been labeled as delinquent since the mortgage was taken out.
} 
origination, but in an environment of declining interest rates such as the one we study, it is cheaper to repurchase bonds at face value as in a US refinancing. ${ }^{9}$

An important point is that mortgage bonds in Denmark are issued with discrete coupon rates, historically at integer levels and more recently at 50-basis point intervals. Market yields, of course, fluctuate continuously. Danish mortgage bonds can never be issued at a premium to face value, since this would allow instantaneous advantageous refinancing, and normally are issued at a discount to face value; in other words, the market yield is somewhat above the discrete coupon at issue. This implies that to raise, say, DKK 1 million for a mortgage, bonds must be issued with a face value which is higher than DKK 1 million. Refinancing the mortgage in an environment of falling rates requires buying the full face value of the bonds that were originally issued to finance it. Therefore the interest saving from refinancing in the Danish system is given by the spread between the coupon rate on the old mortgage bond (not the yield on the mortgage when it was issued) and the yield on a new mortgage.

Similarly, refinancing increases mortgage principal because new bonds must be issued at a discount to repurchase the old ones. However, such a transaction does not count as a cash-out refinancing provided that the market value of the newly issued mortgage bonds is no greater than the face value of the old mortgage bonds plus any refinancing costs that have been borrowed as part of the refinancing.

Importantly, this increase in mortgage principal has a much smaller impact on Danish borrowers than it would do in the US mortgage system. Danish borrowers have the option to pay off their mortgage at market value or face value (an option that survives even in the event of default); and at mortgage origination market value is below face value, so market value is the relevant measure of the burden of the debt. The higher face value becomes relevant only in the event that interest rates decline far enough for borrowers to consider a second refinancing. In that event, the refinancing

\footnotetext{
${ }^{9}$ In a rising interest-rate environment, the option to repurchase bonds at market value is a valuable feature of the Danish mortgage system. It prevents "lock-in" by allowing homeowners who move to buy out their old mortgages at a discounted market value rather than prepaying at face value as is required in the US system. It also allows homeowners to take advantage of disruptions in the mortgage bond market by effectively buying back their own debt if a mortgage-bond fire sale occurs.
} 
incentive will once again be the spread between the coupon rate on the mortgage bond and the currently prevailing yield. ${ }^{10}$

Cash-out refinancing does require sufficiently positive home equity and good credit status. For this reason, cash-out refinancing has been less common in Denmark in the period we examine since the onset of the housing downturn in the late 2000 s. In our dataset $26 \%$ of refinancings are associated with an increase in mortgage principal of $10 \%$ or more, enough to classify these as cash-out refinancings with a high degree of confidence. In the paper we present results that include these refinancings, but in section 4.5 we show that our results are robust to excluding them.

\subsection{Danish household data}

\section{A. Data sources}

Our dataset covers the universe of adult Danes in the period between 2009 and 2017, and contains both demographic and economic information about this population. We derive data from four different administrative registers made available through Statistics Denmark.

We obtain mortgage data from the Danmarks Nationalbank, which in turn obtains the data from mortgage banks through the Association of Danish Mortgage Banks (Realkreditrådet) and the Danish Mortgage Banks' Federation (Realkreditforeningen). The data are annual and cover all mortgage banks and all mortgages in Denmark. ${ }^{11}$ We have personal identification numbers for borrowers, identification numbers for mortgages, and information on mortgage terms (principal, outstanding principal, coupon, annual fees, maturity, loan-to-value, issue date, etc.)

We obtain demographic information from the Danish Civil Registration System (CPR Registeret). These records cover the entire Danish population and include each individual's personal

\footnotetext{
${ }^{10}$ We are grateful to Susan Woodward for discussions on this point.

${ }^{11}$ The data use agreement requires us to merge data from all mortgage banks and does not allow us to study variation across banks. The Danish mortgage market is competitive and offers virtually homogeneous products, with minimal rate variation across banks. Consequently, we believe that bank-specific effects are not of first-order importance for our inferences.
} 
identification number (CPR), as well as their name, gender, date of birth, and marital history (number of marriages, divorces, and history of spousal bereavement). The records also contain a unique household identification number, as well as CPR numbers of each individual's spouse and any children in the household. We use these data to obtain demographic information about mortgage borrowers.

We obtain income and wealth information from the Danish Tax Authority (SKAT). This dataset contains total and disaggregated income and wealth information by CPR numbers for the entire Danish population. SKAT receives this information directly from the relevant third-party sources, because employers supply statements of wages paid to their employees, and financial institutions supply information to SKAT on their customers' deposits, interest paid (or received), security investments, and dividends. Because taxation in Denmark mainly occurs at the source level, the income and wealth information are highly reliable.

Some components of wealth are not recorded by SKAT. The Danish Tax Authority does not have information about individuals' holdings of unbanked cash, the value of their cars, debt owed to private individuals, defined-contribution pension savings, private businesses, or other informal wealth holdings. This leads some individuals to be recorded as having negative net financial wealth because we observe debts but not corresponding assets, for example in the case where a person has borrowed to finance a new car.

Finally, we obtain the level of education from the Danish Ministry of Education (Undervisningsministeriet). This register identifies the highest level of education and the resulting professional qualifications. On this basis we calculate the number of years of schooling.

\section{B. Sample selection}

Our sample selection entails linking individual mortgages to the household characteristics of borrowers. We define a household as one or two adults living at the same postal address. To be able to credibly track the ownership of each mortgage we additionally require that each household has an unchanging number of adult members over two subsequent years. This allows us to identify 
2,698,011 Danish households overall in 2009 (the number of households increases slightly over time, to $2,884,184$ in 2017$)$.

To operationalize our analysis of refinancing, we begin by identifying households with a single fixed-rate mortgage. This is done in four steps, year-by-year. First we identify households holding any mortgages in a given year, leaving us with, for example, 960,159 households in 2009. Second, to simplify the analysis of refinancing choice, we focus on households with a single mortgage observed in two consecutive years, leaving us with 641,786 households in the 2009-2010 consecutive year period. Third, we focus on households with fixed-rate mortgages, as these are the households who have financial incentives to refinance when interest rates decline. This leaves us with 330,350 households holding a single fixed-rate mortgage which we can track in the 2009-2010 consecutive year period. Following this approach to data construction, our final sample has 2,376,815 household observations across the eight years. Finally, we expand the data to the quarterly frequency using mortgage issue dates reported in the annual mortgage data, giving us a total of 9,351,183 householdquarters during which we can study refinancing decisions. ${ }^{12}$

We observe a total of 378,421 refinancings across the eight years, i.e., a refinancing rate of approximately 4\%. Of these refinancings, 113,333 were from fixed-rate to adjustable-rate mortgages, and 265,088 from fixed-rate to fixed-rate mortgages (or in a small minority of cases, to capped adjustable-rate mortgages which have similar properties to true fixed-rate mortgages). We treat both types of refinancings in the same way and do not attempt to model the choice of an adjustablerate versus a fixed-rate mortgage at the point of refinancing. ${ }^{13}$

Collectively, our selection criteria ensure that the refinancings we measure are undertaken for economic reasons. Refinancing in our sample occurs when a household changes from one fixed-rate mortgage to another mortgage (whether it is fixed- or adjustable-rate) on the same property. Mort-

\footnotetext{
${ }^{12}$ This is less than the number of yearly observations times four, because some households refinance from a fixedrate mortgage to an adjustable-rate mortgage, and drop out of the sample in subsequent quarters in the year. Our imputation of quarterly refinancings will be incorrect if a mortgage refinances twice in the same calendar year (since only the second refinancing will be recorded at the end of the year), but we believe this event to be exceedingly rare.

${ }^{13}$ The comparison of adjustable- and fixed-rate mortgages is complex and has been discussed by Dhillon, Shilling, and Sirmans (1987), Brueckner and Follain (1988), Campbell and Cocco (2003, 2015), Koijen, Van Hemert, and Van Niewerburgh (2009), Johnson and Li (2014), and Badarinza, Campbell, and Ramadorai (2017) among others. We verify in section 4.5 that our results are robust to excluding refinancings from fixed- to adjustable-rate mortgages.
} 
gage terminations that are driven by household-specific events, such as moves, death, or divorce, are treated separately by predicting the probability of mortgage termination, and using the fitted probability as an input into our models of optimal refinancing. This approach differs from that of the US prepayment literature, which seeks to predict all mortgage terminations regardless of their cause.

\section{Deviations from Rational Refinancing}

\subsection{The optimal refinancing threshold}

A household should refinance when its incentive to do so is positive. We write the incentive as $I_{i t}$, to indicate that it depends on the characteristics of household $i$ and the household's mortgage at time $t$. In the Danish context the incentive is the coupon rate on the mortgage bond corresponding to the current mortgage $C_{i t}^{\text {old }}$, less the interest rate on a new mortgage $Y_{i t}^{\text {new }}$, less a threshold level $O_{i t}$, which again depends on household and mortgage characteristics:

$$
I_{i t}=\left(C_{i t}^{\text {old }}-Y_{i t}^{\text {new }}\right)-O_{i t}
$$

Optimal refinancing of a fixed-rate mortgage, given fixed costs of refinancing, is a complex real options problem. The optimal refinancing threshold $O_{i t}$ takes the fixed cost of refinancing into account, and captures the option value of waiting for further interest-rate declines. To measure $O_{i t}$, for our main analysis we adapt a formula due to Agarwal, Driscoll, and Laibson (ADL 2013). (In section 4.5 we verify that our results are not sensitive to this specific formulation of the threshold, by recomputing the threshold using the approach of Chen and Ling (1989)). The ADL model assumes that mortgages have an infinite maturity with principal declining at an exogenous constant rate, that mortgages may be refinanced multiple times, that mortgage borrowers are risk-neutral with respect to refinancing proceeds, and that the mortgage interest rate follows an arithmetic random 
walk. The last assumption approximates the behavior of the long-term interest rate in standard term structure models, because substantial predictability in long-term interest rate changes would imply highly profitable trading strategies in long-term bonds which are ruled out by such models.

ADL's closed-form solution for the refinancing threshold $O_{i t}$ is:

$$
\begin{aligned}
O_{i t} & =\frac{1}{\psi_{i t}}\left[\phi_{i t}+W\left(-\exp \left(-\phi_{i t}\right)\right)\right], \\
\psi_{i t} & =\sqrt{\frac{2\left(\rho+\lambda_{i t}\right)}{\sigma}} \\
\phi_{i t} & =1+\psi_{i t}\left(\rho+\lambda_{i t}\right) \frac{\kappa\left(m_{i t}\right)}{m_{i t}(1-\tau)} .
\end{aligned}
$$

Here $W($.$) is the Lambert W$-function, and $\psi_{i t}$ and $\phi_{i t}$ are two household-specific inputs to the formula, which in turn depend on interpretable marketwide and household-specific parameters. The marketwide parameters are $\rho$, the discount rate; $\sigma$, the volatility of the annual change in the interest rate; and $\tau$, the marginal tax rate that determines the tax benefit of mortgage interest deductions. Although the Danish tax system is progressive, the tax benefit of mortgage interest deductions is applied at a fixed tax rate, consistent with ADL's assumptions. We calibrate these parameters using a mixture of the recommended parameters in ADL and sensible values given the Danish context, setting $\sigma=0.0074, \tau=0.33$, and $\rho=0.05$.

An important household-specific parameter is $m_{i, t}$, the size of the mortgage for household $i$ at time $t$. This determines $\kappa\left(m_{i, t}\right)$, the monetary refinancing cost. We establish from a sample of price lists obtained from Danish mortgage banks, and from conversations with these banks, that the total DKK monetary cost of refinancing is well approximated by

$$
\kappa\left(m_{i, t}\right)=3000+\max \left(0.002 m_{i, t}, 4000\right)+0.001 m_{i, t} .
$$

The first two terms correspond to bank handling fees in the range DKK 3,000-7,000 (about US\$ $450-1,050)$ and the third term represents the cost incurred to trade mortgage bonds to implement the refinancing. For extremely large mortgages, the third term may not increase directly with the 
size of the new mortgage (as there are significant incentives for wealthy households to shop, and variation across banks in their "capping" policies) so we additionally winsorize $\kappa\left(m_{i, t}\right)$ at the 99th percentile of (5), a value just below DKK 10,000 (about \$1,500). This additional winsorization does not make a material difference to our results.

The remaining household-specific parameter is $\lambda_{i, t}$, the expected rate of decline in the real principal of the mortgage for reasons other than rate-reducing refinancing. Following ADL we define $\lambda_{i, t}$ as

$$
\lambda_{i, t}=\mu_{i, t}+\frac{Y_{i, t}^{\text {old }}}{\exp \left(Y_{i, t}^{\text {old }} T_{i, t}\right)-1}+\pi_{t} .
$$

The three terms in this expression are the exogenous mortgage termination hazard $\mu_{i, t}$, the rate of nominal principal paydown, and the inflation rate $\pi_{t}$. We estimate $\mu_{i, t}$ at the household level using additional data in an auxiliary regression. Mortgage termination can occur for many reasons, including the household relocating and selling the property, experiencing a windfall and paying down the principal amount, or simply because the household ceases to exist because of death or divorce. (We infer these events from the register data, and of course, exclude refinancing from the definition of mortgage termination.) Without seeking to differentiate these causes, we use all households with a single fixed-rate mortgage and estimate, for each year in the sample,

$$
\mu_{i, t}=p(\text { Termination })=p\left(\mu^{\prime} z_{i t}+\epsilon_{i t}>0\right)
$$

where $\epsilon_{i t}$ is a standard logistic distributed random variable, using a vector $z_{i t}$ of household characteristics. $^{14}$

The remaining variables in (6) are $Y_{i t}^{\text {old }}$, the yield on the household's pre-existing ("old") mortgage; $T_{i, t}$, the number of years remaining on the mortgage; and $\pi_{t}$, the inflation rate. We calculate the yield on the old mortgage using mortgage bond yields in 10-year maturity bands. ${ }^{15}$ We set $\pi_{t}$

\footnotetext{
${ }^{14}$ Online Appendix Table B1 reports the estimated coefficients, and Figure B1 shows a histogram of the estimated mortgage termination probabilities, with a dashed line showing the position of the ADL suggested "hardwired" level of $10 \%$ per annum. The mean of our estimated termination probabilities is $11.4 \%$, larger than the median of $8.1 \%$ because the distribution of termination probabilities is right-skewed. The standard deviation of this distribution is $10.1 \%$.

${ }^{15}$ That is, in each quarter, for mortgages with 10 or fewer years to maturity, we use the average 10 year mortgage
} 
equal to realized consumer price inflation over the past year, a standard proxy for expected inflation that varies between $2.0 \%$ and $3.0 \%$ during our sample period.

Figure 1 plots the ADL threshold level in basis points associated with each fixed cost in DKK. The figure shows that the ADL threshold is a concave function of fixed costs, but becomes roughly linear at high levels of fixed costs. The level and slope of the function are considerably greater for smaller mortgages, and slightly greater for older mortgages with shorter remaining time to maturity, because fixed costs are more important relative to interest savings for these mortgages. This implies that for any given mortgage, the threshold rises over time as principal is paid down and remaining maturity declines; hence, the incentive to refinance declines over time if the interest rate remains unchanged. This effect is small for new mortgages (and for most of the mortgages in our sample), but it becomes increasingly important as mortgages age. In section 4.5 we discuss the sensitivity of the threshold to the parameters we have assumed.

We note two minor limitations of the ADL formula in our context. First, it gives us the incentive for a household to refinance from a fixed-rate mortgage to another fixed-rate mortgage. Some households in our sample refinance from fixed-rate to adjustable-rate mortgages, implying that they perceive a new ARM as even more attractive than a new FRM. We do not attempt to model this decision here but simply use the ADL formula for all initially fixed-rate mortgages and refinancings, whether or not the new mortgage carries a fixed rate. We verify in section 4.5 that our results are robust to excluding FRM-to-ARM refinancings.

Second, the ADL formula ignores the fact, unique to the Danish system, that refinancing may increase the mortgage principal balance because the coupon on the new mortgage bond is lower than the market yield. Because Danish households have the option to pay off a mortgage at market value, which is below face value immediately after a refinancing, this increase in the mortgage principal has no economic effect except in the event that interest rates decline in the future to the point where the household considers refinancing the new mortgage. The value of the refinancing

bond yield to compute incentives, and for remaining tenures between 10-20 years (greater than 20 years) we use the average 20 year (30 year) bond yield. These 10, 20, and 30 year yields are calculated as value-weighted averages of yields on all newly issued mortgage bonds with maturities of 10, 20, and 30 years, respectively. 
option attached to the new mortgage is determined by the new mortgage bond coupon, and is lower than that assumed by the ADL formula whenever that coupon is lower than the current market yield, in other words, whenever the mortgage principal increases. In section 4.5, we bound the magnitude of this effect by comparing the ADL model with an alternative model due to Chen and Ling (1989) that excludes subsequent refinancings entirely.

\subsection{Refinancing and incentives}

Table 1 summarizes the characteristics of Danish fixed-rate mortgages, and households' propensity to refinance them. As mentioned earlier, we have over 9.3 million quarterly observations of household mortgages. The average mortgage has an outstanding principal of DKK 983,000 (about $\$ 147,000)$, just over 23 years to maturity, and a loan-to-value ratio of $60 \%$. These characteristics are fairly stable over our sample period, although principal and loan-to-value ratios do increase somewhat in later years.

The average refinancing rate in our sample is $4 \%$ per quarter, and among these, $70 \%$ are refinanced to fixed-rate mortgages, and $30 \%$ to adjustable-rate mortgages. The incentive to refinance, calculated using coupon rates on outstanding mortgage bonds in relation to current mortgage yields less the threshold estimated from the ADL formula (1) from the previous section, is negative for $56 \%$ of the household-quarter observations and positive for the remaining $44 \%$. The refinancing rate is much lower at negative incentives (1.3\%) than at positive incentives $(7.6 \%)$.

Figure 2 illustrates the cross-sectional distribution of incentives and refinancing activity in greater detail. ${ }^{16}$ The top panel of the figure is a histogram of incentives, treating each householdquarter as a separate observation. The distribution of incentives is centered slightly to the left of zero, but with a long right tail, including some incentives well above $2 \%$. The frequency of refinancing at each incentive is superimposed on this histogram: it rises from a low level in the neighborhood of a zero incentive, peaks at an incentive around $1.25 \%$, and declines at higher incentives.

\footnotetext{
${ }^{16}$ Online Appendix Table B2 reports year-by-year quantiles of this distribution.
} 
The second panel of Figure 2 is a histogram of incentives at which refinances occur, treating each refinancing as a separate observation. The increase in the refinancing rate at positive incentives, shown in the top panel, shifts the histogram in the second panel to the right relative to the histogram in the top panel. Most refinances occur at modest positive incentives, but about $18 \%$ occur at negative incentives and others at large positive incentives.

The third panel of Figure 2 illustrates the tendency for refinancing to be substantially delayed relative to the first date at which a household has a positive incentive to refinance. The figure plots the Kaplan-Meier survival curve for mortgages with positive incentives, taking account of censoring caused either by a return to a negative incentive, or by the end of the sample period. The figure shows that even four years after a positive incentive is reached, about half of mortgages have still failed to refinance.

Figure 3 illustrates the dynamics of refinancing in relation to refinancing incentives. The top panel is a bar chart that shows the number of refinancings in each quarter. Our sample includes three large refinancing waves, in 2010, 2012, and 2014-15, and a smaller refinancing wave in 2016-17. Between these waves there were quiet periods in 2011, 2013, and late 2015.

The components of each bar are shaded to indicate the coupon rate of the refinancing mortgage, with high coupons shaded pale blue and low coupons shaded dark blue, from $6 \%$ or above at the high end to below $3 \%$ at the low end. Unsurprisingly the higher coupons tend to refinance earlier in our sample period.

The bottom panel of Figure 3 plots the Danish mortgage interest rate (measured as the minimum average weekly mortgage rate during each quarter) as a solid line declining over the sample period from almost $5 \%$ to below $2 \%$, with upticks that align with the quiet periods of low refinancing activity. The horizontal colored lines in this panel show the average ADL refinancing thresholds for mortgages with each coupon rate from $6 \%$ to $2.5 \%$. Taken together, the top and bottom panels of the figure show that each refinancing wave is dominated by mortgages for which the interest rate has already passed the ADL threshold. This is another way to see that Danish mortgage borrowers do not respond promptly to positive ADL refinancing incentives. 


\subsection{Taking account of heterogeneous refinancing thresholds}

The evidence reported so far could be consistent with a pure state-dependent model in which households have heterogeneous unobserved refinancing thresholds. If we had a single cross-section of mortgage refinancing, we could never reject such a model. The observed refinancing rate by ADL incentive in the top panel of Figure 2 would tell us the fraction of households at each ADL incentive level that have a positive incentive relative to their own unobserved threshold, but the model would not place any restrictions on the data.

Because we observe households over time, we can use the dynamics of refinancing to show that a pure state-dependent model is inadequate to explain Danish household behavior. Panel B of Table 1 reports summary statistics by household. Of the 614,811 households in our dataset, almost 50\% never refinance, $40 \%$ refinance once, $9 \%$ refinance twice, and 1\% refinance three or more times. Once a single refinancing has been observed, the pure state-dependent model has two strong implications that contrast with graphical evidence shown in Figure 4.

First, a household that refinances should never do so at an ADL incentive that is lower than the highest incentive it has previously experienced. For the $50 \%$ of households that refinance at least once in our dataset, the top panel of Figure 4 shows the histogram of the difference between the incentive at the refinancing date and the highest previous incentive. This difference is frequently negative (35\% of observations), implying that households could have got better rates by refinancing earlier. This finding is particularly striking since the downward trend in interest rates during our sample period implies that increases in refinancing incentives are more common than declines.

Second, a household that has refinanced once should always refinance again when the same ADL incentive is reached. For the $10 \%$ of households that refinance at least twice in our dataset, the middle panel of Figure 4 shows the distribution of the difference between the incentive at second refinancing and the incentive at first refinancing. This distribution is extremely dispersed, with a standard deviation of 327 basis points, contrary to the point mass at zero implied by a pure state-dependent model. 
The pattern in the middle panel cannot be explained by short delays in household refinancing decisions. The bottom panel of Figure 4 shows the Kaplan-Meier survival curve after a mortgage that has been refinanced once reaches the ADL incentive that previously triggered refinancing. It is common for mortgages to go several years without refinancing in these circumstances.

\subsection{Household characteristics and the costs of slow refinancing}

How do observable household characteristics affect refinancing behavior? In Online Appendix Table B3 we provide a comprehensive set of descriptive statistics for all households with a fixedrate mortgage. In our full sample, $25 \%$ of all households consist of a single member, and $63 \%$ are married couples. The remainder are cohabiting couples. $41 \%$ of households have children living in the household. In each year an average $1 \%$ of households got married and $4 \%$ experienced the birth of a child.

We have direct measures of financial literacy, defined as a degree in finance or economics, or professional training in finance, for at least one member of the household. $6 \%$ of households are financially literate in this strong sense. A larger fraction of households, $16 \%$, have members of their extended family (including non-resident parents, siblings, in-laws, or children) who are financially literate.

The table also compares household characteristics between refinancing and non-refinancing households (measured in January of each year). Refinancers are more likely to be married and to have children, and less likely to be single. They are also more likely to be experiencing important life events such as marriage or the birth of a child. Our two measures of financial literacy are also higher for refinancing households.

In our empirical analysis we use demeaned ranks of age, education, income, financial wealth, and housing wealth rather than the actual values of these variables. Online Appendix Table B4 reports selected percentiles of the underlying distribution for all households, and separately for refinancing and non-refinancing households. A comparison of ranked variables across refinancers 
and non-refinancers shows that refinancers are younger and better educated, and have higher income and housing wealth but lower financial wealth. We find similar patterns when we look separately at households with positive and negative ADL refinancing incentives in Online Appendix Table B5, or when we estimate logit refinancing models that include all demographic variables simultaneously with refinancing incentives.

Older and less educated households with lower income and housing wealth refinance less often. As a way to quantify the ex post costs of this behavior in our sample period, we follow households through the sample and compare the interest savings realized from households' actual refinancing decisions with those that would have been realized by an optimal strategy of refinancing at the ADL threshold in each quarter. We call the difference between these two savings "missed" interest rate savings, a measure of the cost of slow refinancing along the particular path that interest rates followed in our sample. The procedure allows households to refinance multiple times if it would have been optimal to do so. Savings are calculated as a percentage of mortgage principal, in DKK, and as a percentage of household income and then averaged across households. Results are reported in Online Appendix Table B6.

As a percentage of mortgage principal, we estimate an average of 55 basis points of realized savings across all households in all years of our sample, but 98 basis points of optimal savings implying 43 basis points of missed savings. Missed savings average DKK 2,700 per year and 58 basis points of household income.

On average, missed savings are substantial and positive in all quarters of our sample. This is true despite the fact that, along a path of declining interest rates, delayed refinancing can result in a lower interest rate after refinancing and hence an ex post benefit at the end of our sample period. While some households do pay lower rates at the end of the sample than they would have if they had refinanced optimally, this is not the case on average - which may not be surprising in light of the fact that almost $50 \%$ of households in our sample do not refinance at any time during our sample period.

When we sort households into quintiles by ranked variables we find that older people, less 
educated people, and people with lower income and housing wealth realize smaller savings and miss greater savings as a percentage of their mortgage principal. In contrast, people with greater financial wealth have slightly lower realized savings and considerably greater missed savings as a percentage of mortgage principal, possibly connected to their higher opportunity costs of paying attention to the mortgage refinancing decision. Missed savings can be a substantial fraction of income for some groups: for example, they average 86 basis points of income for households in the lowest education quintile and 118 basis points of income for households in the lowest income quintile.

Figure 5 summarizes these patterns graphically. The figure plots refinancing efficiency, defined as the ratio of realized savings to optimal savings in DKK, across quintiles of the distribution for age, education, income, financial wealth, and housing wealth. Refinancing efficiency is hump-shaped in age with a peak around $75 \%$ at roughly the 25 th percentile of age in the sample, and a decline among older households to about $60 \%$. It increases with education, income, and housing wealth from about $50 \%$ to about $75 \%$, and is fairly flat around $70 \%$ in relation to financial wealth. These estimates support the concern expressed by Miles (2004), Campbell (2006), Agarwal, Rosen, and Yao (2016), and Keys, Pope, and Pope (2016) that the mortgage refinancing decision is challenging for some people. We now estimate a structural refinancing model to gain greater insight about the nature of this challenge.

\section{A Model of Slow Refinancing}

\subsection{A mixture model of refinancing behavior}

\section{A. State-dependent inaction: refinancing with psychological costs}

Consider a model of mortgage choice in which the probability that a household $i$ refinances its fixed-rate mortgage at time $t$ (the event $y_{i t}=1$ ) depends on the household's perceived refinancing incentive, its responsiveness to the incentive, and a standard logistic distributed stochastic choice 
error $\epsilon_{i t}$ following Luce (1959).

The refinancing probability of the household $i$ at time $t$ can be written as

$$
p_{i, t}\left(y_{i, t}=1 \mid z_{i t} ; \varphi, \theta_{i}, \beta\right)=p\left(\exp (\beta) I^{*}\left(z_{i t} ; \varphi, \theta_{i}\right)+\epsilon_{i t}>0\right)
$$

Here $z_{i t}$ is a set of household and mortgage characteristics at time $t$. The parameter vector $\varphi$ and the household-specific scalar $\theta_{i}$ interact with those characteristics to determine the level of the refinancing incentive $I^{*}$. The scalar parameter $\beta$ governs the household's responsiveness to the incentive; for simplicity we do not allow this parameter to vary across households.

We model the refinancing incentive using the ADL model from the previous section, with one important change. The refinancing cost $\kappa\left(m_{i t}\right)$, which in the rational model depends only on the size of the mortgage $m_{i t}$, is now replaced by:

$$
\kappa^{*}\left(m_{i t}, z_{i t} ; \varphi\right)=\kappa\left(m_{i t}\right)+\exp \left(\varphi^{\prime} z_{i t}+\theta_{i}\right)
$$

where

$$
\theta_{i} \sim N\left(0, \sigma_{\theta}^{2}\right)
$$

Here observable characteristics $z_{i t}$ add a psychological component to the refinancing cost through the term $\varphi^{\prime} z_{i t}$. The effect of household characteristics captures a great deal of the observed heterogeneity in refinancing behavior. However, there still may be heterogeneity related to unobservables, and this is captured by the random variable $\theta_{i}$ which has cross-sectional variance $\sigma_{\theta}^{2}$. The modified refinancing incentive $I^{*}\left(z_{i t} ; \varphi, \theta_{i}\right)$ is given by equations (1)-(7), replacing (5) with (9).

For given $\theta_{i}$, this specification implies that the likelihood contribution of each household choice is:

$$
\mathcal{L}_{i t}\left(\varphi, \theta_{i}, \beta\right)=\Lambda\left(\left[2 y_{i, t}-1\right]\left[\exp (\beta) I^{*}\left(z_{i t} ; \varphi, \theta_{i}\right)\right]\right)
$$

where $\Lambda($.$) is the inverse logistic function, \Lambda(x)=\exp (x) /(1+\exp (x))$. This model of household choice underlies the commonly used logit regression. 
When $\sigma_{\theta}^{2}>0, \theta_{i}$ is random, and in this case we have a model with random coefficients. Estimation of such a model can be undertaken using maximum simulated likelihood (MSL) methods. The essential idea of MSL methods is to evaluate the likelihood for random draws of $\theta_{i}$ for each household from the proposed distribution of $\theta_{i}$, and then to average these simulated likelihoods. So each likelihood evaluation involves $H$ extra evaluations, where $H$ is the number of random draws from the distribution. Advances in computational power, and clever ways of drawing random sequences to ensure good coverage of the intended density with minimal $H$, make it feasible to undertake MSL for a problem such as ours. ${ }^{17}$

\section{B. Time-dependent inaction: a mixture model}

To capture the phenomenon of time-dependent inaction, we use a mixture model. ${ }^{18}$ We assume that households can be in one of two states which we call "awake" and "asleep". In each period a household is asleep with probability $w_{i t}$ and awake with probability $1-w_{i t}$, where $0<w_{i t}<1$. Awake households refinance with the probability given above in equation (8). Asleep households refinance with zero probability, which can be captured numerically by altering (8) to have a large negative refinancing incentive.

The probability that a household is asleep in any period is modeled by

$$
w_{i t}(\chi)=\frac{\exp \left(\chi^{\prime} z_{i t}\right)}{1+\exp \left(\chi^{\prime} z_{i t}\right)}
$$

The likelihood contribution for household $i$ is a finite mixture of proportions:

$$
\mathcal{L}_{i t}\left(\chi, \varphi, \theta_{i}, \beta\right)=w_{i t}(\chi) \mathcal{L}_{i t}^{a s l e e p}\left(\varphi, \theta_{i}, \beta\right)+\left(1-w_{i t}(\chi)\right) \mathcal{L}_{i t}^{\text {awake }}\left(\varphi, \theta_{i}, \beta\right) .
$$

\footnotetext{
${ }^{17}$ Standard references include Gouriéroux and Monfort (1996), Train (2009), and Cameron and Trivedi (2005). Gaudecker, Soest and Wengström (2011) and Handel (2013) are recent applications of the methods that we employ.

${ }^{18}$ Mixture models have a long history in statistics since Pearson (1894). A recent survey is presented in McLachlan and Peel (2000). Two applications where mixture models are used to uncover decision rules are El-Gamal and Grether (1995) for Bayesian updating behavior, and Harrison and Rutström (2009) for models of decision-making under risk.
} 
This leads to the household log likelihood function over our sample specified as:

$$
\ln \mathcal{L}\left(\chi, \varphi, \theta_{i}, \beta\right)=\sum_{t} \sum_{i} \ln \left(\mathcal{L}_{i t}\left(\chi, \varphi, \theta_{i}, \beta\right)\right)
$$

This framework models deviations from rational refinancing using two parameter vectors $\chi$ and $\varphi$, a scalar parameter $\sigma_{\theta}^{2}$ that governs the variance of $\theta_{i}$ in equation (14), and a scalar parameter $\beta$. The parameter vector $\chi$ captures the demographic determinants of the probability that a household is awake and responding to refinancing incentives in a given period. The parameter vector $\varphi$ determines whether particular demographic characteristics are associated with higher or lower psychological refinancing costs. The scalar parameter $\sigma_{\theta}^{2}$ captures unobserved permanent heterogeneity in household psychological refinancing costs. Finally, the scalar parameter $\beta$ determines the responsiveness of households in each period to the modified refinancing incentive. One interpretation of this parameter is that it reflects unobserved household-level shocks to the refinancing threshold, which are uncorrelated both across households and over time.

In any cross-section these parameters determine a set of curves, each of which relates the refinancing frequency for a household with a given set of demographic characteristics to the ADL refinancing incentive at a point in time. The model implies that each curve has a logistic form, close to zero for highly negative incentives and positive for highly positive incentives. The height of the curve for highly positive incentives measures the probability that the given type of household is awake. The horizontal position of the point where the curve reaches half this height measures the increment to the ADL threshold implied by the average psychological refinancing costs for this type of household. The slope of the curve at this point is governed by the parameters $\sigma_{\theta}^{2}$ and $\beta$, which for simplicity we do not allow to vary with household demographics.

Together, the model's parameters govern household behavior over time and tell us the relative importance of time-dependent and state-dependent inaction in explaining failures to refinance. For example, if the parameters $\varphi$ and $\sigma_{\theta}^{2}$ are estimated to be zero, then there are no psychological costs of refinancing. In this case every household will eventually refinance whenever they face a positive ADL incentive to do so, implying that the problem is time-dependent inaction. If on the other hand 
the parameters $\chi$ imply that households are always awake, then households will refinance whenever they reach the threshold determined by their particular psychological refinancing costs, implying that state-dependent inaction is the cause of refinancing failures. In the former case, a modest decline in interest rates will eventually induce all households to refinance, whereas in the latter case a sizeable interest rate movement is required for some households to overcome the psychological costs that inhibit refinancing.

\subsection{Comparing alternative specifications}

We first explore the relative importance of the various elements of our model. Table 2 reports parameter estimates for a series of models with an increasing number of parameters. We do not report standard errors for the estimated parameters, since all coefficients are statistically significant at the $1 \%$ level or less. Instead, we summarize the fit of each model using a pseudo $R^{2}$ statistic based on the log likelihood of the model relative to Model 4, the model which includes both statedependent and time-dependent inaction, restricted to be the same for all households and time periods.

All models include the parameter $\beta$, and in Model 1 , this is the sole parameter. The estimate of $\beta$ in Model 1 is -1.35 , indicating that each 1 basis point change in the incentive in the neighborhood of a zero incentive increases the refinancing probability by only 6 basis points. The relative fit of this model is very poor, since it implies a refinancing rate that is too high on average and varies little with refinancing incentives.

Model 2 adds a scalar psychological refinancing cost $\varphi$, equal for all households, to this basic model. The fit of the model improves somewhat but the estimate of $\beta$ is still very low and the estimated $\varphi=6.13$ is unreasonably high, implying a psychological refinancing cost of 457,602 DKK, or approximately $\$ 69,000$.

Model 3 eliminates $\varphi$ but adds a scalar parameter $\chi$ governing the probability that households are asleep, which is equal for all households. The estimated magnitude of $\chi=2.38$ implies that 
$92 \%$ of households are asleep in any given quarter. In this model, $\beta$ is estimated to be 1.30 implying a 92 basis point response of the refinancing probability to the incentive around zero for the $8 \%$ of households who are awake. This model fits considerably better than Model 2, another indication that time-dependent inaction is important to explain Danish household behavior.

Model 4 includes both $\varphi$ and $\chi$ parameters in addition to $\beta$. The fit of the model further improves, and the estimated parameters appear sensible. Estimated $\varphi=2.44$ in this model implies a more realistic psychological cost of 11,439 DKK, or approximately US $\$ 1,716$. From Table 1 , $44 \%$ of the household-quarter observations are above the ADL threshold. Augmenting the ADL threshold by 11,439 DKK implies that only $12 \%$ of household-quarters are above the augmented threshold. The estimated magnitude of $\chi$ implies that $84 \%$ of households are asleep each quarter. Finally, $\beta$ of 0.75 implies a 47 basis point response of the refinancing probability to the incentive around zero for the $16 \%$ of households who are awake.

Model 5 adds unobserved heterogeneity in psychological refinancing costs by estimating a free parameter $\sigma_{\theta}^{2}$ using the MSL method. While this parameter, like all others in the table, is statistically significant at the $1 \%$ level, the improvement in pseudo $R^{2}$ is modest, at $0.7 \%$.

Models 6 through 9 explore the importance of adding time effects and mortgage age effects to the reference Model 4. These can be added either to the psychological refinancing cost $\varphi$ or to the asleep probability $\chi$. Model 6 adds time effects to $\varphi$, and Model 7 also adds mortgage age effects to $\varphi$. Model 8 instead adds time effects to $\chi$, and Model 9 also adds mortgage age effects to $\chi$.

Models 6 and 8 show large gains in pseudo $R^{2}$ from adding time effects, implying that the refinancing waves illustrated in Figure 3 are not simply the result of interest rate declines pushing households across fixed thresholds, but also result from shifts over time in household responses to incentives. However, the improvement in explanatory power is considerably greater in Model 8, at $4.1 \%$, than in Model 6, at 2.9\%. In other words, the intuitive procedure of including time effects in the time-dependent element of the model - the probability that households are asleep - delivers a superior fit. 
Mortgage age effects also contribute to explanatory power, and again the fit is superior when these effects are added to the asleep probability $\chi$ rather than the psychological refinancing $\operatorname{cost} \varphi$. Model 9, the best model considered so far, has a pseudo $R^{2}$ of $5.2 \%$.

Further gains in explanatory power are obtained by adding demographic variables. Model 10 adds demographic covariates to both $\varphi$ and $\chi$, increasing the pseudo $R^{2}$ to $6.9 \%$. Model 11 adds a free parameter $\sigma_{\theta}^{2}$ to Model 10, estimating the model using the MSL method. The improvement in pseudo $R^{2}$ is extremely small at $0.1 \%$. Given the computational burden of estimating random coefficients models and the negligible improvement in fit, we drop unobserved heterogeneity in psychological refinancing costs from further consideration and proceed with Model 10 as our base case.

The magnitudes of the estimated parameters in Model 10 are sensible. For the reference household in the last quarter of the sample, the estimated $\varphi$ implies psychological refinancing costs of 12,768 DKK or roughly US\$ 1,$914 ; \chi$ implies that $96 \%$ of reference households are asleep in this quarter; and $\beta$ implies a 57 basis point response response of the refinancing probability to the incentive around zero for reference households who are awake. ${ }^{19}$

\subsection{Properties of our baseline model}

We now explore in detail the ability of our baseline model (Table 2, Model 10) to fit the Danish data. Figure 6 shows the sample distribution of incentives, together with the observed sample refinancing probability at each incentive level. As previously discussed, most incentives are negative, but there is a substantial fraction of positive incentives. The observed refinancing probability increases strongly around the zero level, peaking at an incentive slightly above 1\%. Very few observations have positive incentives greater than this, so the observed sample refinancing probability at high incentive levels is based on limited data and is correspondingly noisy.

\footnotetext{
${ }^{19}$ The reference household is an unmarried couple without children, and with no financial literacy in the household or the extended family, living in Copenhagen with median age, education, income, wealth and housing wealth, and with a recently issued mortgage.
} 
Figure 6 also shows our model's predicted refinancing probability, and the estimated average probability that households in each incentive bin are awake. The model-predicted refinancing probability captures the overall cross-sectional pattern of refinancing quite well, although it underpredicts refinancings with extremely negative incentives and overpredicts refinancings with extremely positive incentives, both areas in which the data are sparse. The figure also shows that the probability that households are awake is somewhat noisy across bins, but averages about $10 \%$ for households with negative incentives, rises to $15 \%$ for households with low positive incentives, and declines to about $7 \%$ for households with high positive incentives. This pattern is the result of demographic variation in the population at each incentive level, as incentives do not directly enter our specification for the probability that households are awake.

Figure 7 shows the estimated cross-sectional distribution of refinancing costs and their implications for the interest savings that induces refinancing. The left side of the figure measures refinancing costs in DKK, while the right side reports the implications of these costs for the position of the interest threshold. The top left panel shows financial refinancing costs varying from a little over DKK 3,000 to the upper winsorization point just below DKK 10,000, with a mean of DKK 5,850. The top right panel reports the distribution of the corresponding ADL refinancing threshold, varying from about 50 to about 250 basis points, with a mean of 83 basis points and standard deviation of 37 basis points.

The middle left panel of Figure 7 shows the psychological refinancing costs in DKK, varying from almost zero to about DKK 30,000 with a mean of 10,400. Unsurprisingly, these costs lead to large increases in the threshold that triggers refinancing, as shown in the middle right panel of Figure 7. Threshold increases have a mean that is comparable to the ADL threshold, but a standard deviation that is almost twice as large. Finally, the bottom panels of Figure 7 show the distributions of total refinancing costs and the total threshold that triggers refinancing. The total threshold is shifted to the right and spread out by the psychological refinancing costs, with a mean of 146 basis points and a standard deviation of 60 basis points.

A striking pattern documented in Online Appendix Table B7 is that households' ADL refi- 
nancing thresholds are almost uncorrelated with their psychological refinancing costs in DKK, but are strongly positively correlated with the increments to the refinancing threshold caused by those psychological refinancing costs. The correlation between the ADL threshold and the psychological refinancing cost is -0.02 , but the correlation between the ADL threshold and the psychological increment to the refinancing threshold is 0.87 . The reason for this pattern is that refinancing costs in DKK have a larger impact on the refinancing threshold for smaller, older mortgages as illustrated in Figure 1. Households with these mortgages therefore tend to have both higher ADL thresholds and higher increases in the thresholds caused by their psychological refinancing costs.

Turning to time-dependent inaction, the top panel of Figure 8 reports the cross-sectional distribution of the probability that households were asleep in a typical quarter of our sample (using sample average time effects and mortgage age effects). There is strong time-variation in this distribution as shown in the bottom panel of Figure 8 using a box-whisker plot. Quarters with high refinancing activity are explained by the model not as the result of declines in interest rates that move many households over their refinancing thresholds, but as the consequence of time fixed effects that imply a lower probability that households are asleep in those quarters. ${ }^{20}$ Over the whole sample, the average probability that a household is asleep is $87 \%$, with a standard deviation of $5 \%$ (that includes both cross-sectional variation and variation over time for a given household).

Cross-sectionally, there is a strong negative correlation between the probability that a household is asleep and psychological refinancing costs measured in monetary units. The correlation is -0.66 in a typical quarter (using sample average time effects and mortgage age effects for the asleep probability), as reported in Online Appendix Table B7 and illustrated in Figure B10. ${ }^{21}$ The reason, as we discuss in greater detail below, is that younger households with higher socioeconomic status are more likely to be awake but also have higher psychological refinancing costs in DKK.

\footnotetext{
${ }^{20}$ While time effects are not the focus of our paper, we have verified using Google Trends that internet search activity for Danish refinancing terms moves closely with the refinancing rate (Online Appendix Figure B8) and inversely with the cross-sectional average probability that households are asleep in each quarter (Online Appendix Figure B9). It is also possible that social interactions, of the sort measured by Maturana and Nickerson (2017), contribute to the time effect.

${ }^{21}$ Online Appendix Table B8 estimates a restricted model in which the coefficient vectors $\varphi$ and $\chi$ are proportional to one another, strengthening the negative correlation between the probability that a household is asleep and its psychological refinancing costs. This model has a pseudo $R^{2}$ statistic of $6.4 \%, 0.5 \%$ lower than the baseline model.
} 
Thus time-dependent and state-dependent inaction are strongest for different types of households.

A caveat is that this negative correlation disappears when we measure the psychological increment to the refinancing threshold. The correlation is only -0.002 between the probability that a household is asleep and the psychological threshold increment. The discrepancy arises because young households with high socioeconomic status tend to have larger mortgages whose refinancing thresholds are less sensitive to the level of refinancing costs in DKK.

\subsection{Cross-sectional variation in the determinants of slow refinancing}

We now turn to a more detailed analysis of the mapping between Danish households' demographic characteristics, their probability of considering a refinancing, and their psychological refinancing costs. Table 3 reports estimates of all the demographic effects in our baseline model. Inspection of the coefficients on dummy variables in Table 3 shows that some demographic characteristics are associated with faster refinancing through both channels. Financial literacy of the household or the family has this effect, consistent with recent work highlighting the beneficial impacts of financial education on a range of household finance decisions (see, e.g., Haliassos, Jansson, and Karabulut, 2019), as do life events such as getting married or having children. ${ }^{22}$ On the other hand, there are also characteristics that move people closer to the rational benchmark in one dimension but further away in the other. For example, married couples are more likely to be awake but have higher psychological refinancing costs than unmarried couples, while immigrants have the opposite pattern.

Table 3 also reports the coefficients on ranked variables: age, education, income, financial wealth, and housing wealth. Previous literature has suggested that such variables may have nonlinear effects. For example Agarwal, Driscoll, Gabaix, and Laibson (2009) report nonlinear effects of age on many financial decisions, with financial sophistication increasing among younger people as they

\footnotetext{
${ }^{22}$ The positive effect of life events on refinancing is surprising to the extent that life events raise the value of time. However, life events can induce households to reconsider and alter their financial strategies, as when married couples merge their bank accounts or new parents buy life insurance, and this may also stimulate refinancing.
} 
gain experience, and decreasing among older people perhaps because of cognitive decline. We have tried two different ways to model such nonlinearities, either using a piecewise linear function with a kink at the median (achieved by adding the absolute value of the demeaned rank to the regression), or using a quadratic function (by adding twice the squared demeaned rank, a normalization that allows direct comparison of the coefficients in the two specifications). We find qualitatively similar results with either method and report the quadratic specification in the paper.

To understand the implied marginal effects of ranked variables, Figure 9 plots the variability in the estimated probability of being asleep, the estimated psychological costs of refinancing in DKK, and the estimated psychological increment to the refinancing threshold, as functions of the ranked variables. The figure is based on a two-step procedure in which the full model is used to estimate refinancing probability, and then the fitted refinancing probability is regressed on the demographic variables, including dummy variables, but excluding mortgage characteristics. This procedure implies that the effects of mortgage age and size covariation with demographic characteristics are attributed to those characteristics, rather than holding mortgage variables constant as demographic characteristics vary. It therefore conveys a more accurate impression of how implied behavior varies cross-sectionally in our model.

The top panel of Figure 9 shows that older households are more likely to be asleep, while households with higher education, income, financial wealth, and housing wealth are all less likely to be asleep. These patterns imply that a time-dependent model of inaction is consistent with the lower refinancing efficiency of older households and those with lower socioeconomic status that was illustrated in Figure 5.

The cross-sectional patterns are very different for psychological refinancing costs in DKK, shown in the middle panel of Figure 9. Middle-aged people have higher psychological refinancing costs than younger or older people. Households with higher education, income, financial wealth, and housing wealth all have somewhat higher psychological refinancing costs, helping to explain the negative correlation between these costs and the probability that a household is awake. The bottom panel of Figure 9 plots the psychological increment to the refinancing threshold rather than the costs that 
generate that increment. The cross-sectional patterns are similar in this panel.

One plausible interpretation of these patterns is that some of the psychological DKK refinancing costs estimated by our model correspond to the value of time spent planning and executing a refinancing, since the monetary value of time is likely higher for middle-aged people and for people with higher income and wealth. This interpretation can also explain the result shown in Table 3 that psychological DKK refinancing costs are higher for families with children. ${ }^{23}$

\subsection{Robustness}

In this section we verify that our results are not sensitive to our choice of mortgage sample, to the parameterization of the ADL optimal refinancing model, or to our decision to use the ADL model as our rational refinancing benchmark. We also compare the ADL threshold with the recommendations of Danish financial advisers, and with the behavior of those Danish households who refinance early in their cohort. Finally, we examine the robustness of our results to the logistic functional form assumed in our stochastic choice model.

\section{A. Alternative mortgage samples}

Online Appendix C replicates Table 3 and Figures 4-6 and 8, excluding all cash-out and maturity extension refinancing from our sample. Online Appendix D excludes households that refinance from an FRM to an ARM from the sample, as strictly speaking, the ADL formula applies to FRM-toFRM refinances. Online Appendix E restricts the mortgage sample to include only mortgages with principal value above DKK 250,000 and remaining maturity of at least 20 years. These larger and longer-maturity mortgages have refinancing thresholds that are less sensitive to parameter inputs and the choice of refinancing model. In all of these cases, our model delivers similar results to those reported in the paper.

\footnotetext{
${ }^{23}$ An alternative behavioral interpretation of the middle panel of Figure 9 could be that households think of mortgage savings in proportional terms, and wait to refinance until the interest savings exceed the rational threshold by a given amount, regardless of the size of their mortgage. But under this interpretation all the lines in the bottom panel of Figure 9 should be flat-which is approximately true for education, but not for any of the other lines in the figure.
} 


\section{B. Alternative parameter choices for the ADL model and behavioral refinancing model}

We have explored the sensitivity of the ADL threshold to changes in the assumed parameters. Online Appendix Figure F1 shows that a 50\% reduction in the assumed interest-rate volatility $\sigma$ lowers the threshold by about 20 basis points on average, while Figure F 2 shows that a $50 \%$ reduction in the household's discount rate $\rho$ lowers it by less than 10 basis points. These changes are small enough to have very little impact on our conclusions about household behavior. Unsurprisingly, when we repeat our analysis with these two parameter modifications, in Online Appendices G and $\mathrm{H}$, we obtain similar results to those in the paper.

Online Appendix I assumes a constant mortgage termination probability of $10 \%$, rather than using the estimated mortgage termination probability for all households. This input to the ADL model affects the position of the optimal refinancing threshold, but does not affect the estimates greatly.

Online Appendix $\mathrm{J}$ allows demographic characteristics to affect the parameter $\beta$ that governs household responsiveness to incentives. Results in these cases are again similar to the base case. We have also considered a model in which households are more likely to be awake when interest rates cross discrete "round number" thresholds, but have not found any evidence of such effects.

\section{Alternative model of optimal refinancing}

In a more ambitious exercise, we recompute optimal refinancing thresholds using the approach of Chen and Ling (CL 1989), which differs from the ADL approach in several substantive ways. ${ }^{24}$ The CL model treats mortgages as having a finite maturity, with an early prepayment that occurs (in the absence of refinancing) at a known future date. The short-term interest rate is assumed to follow a geometric Brownian motion, and a term structure model is used to derive the corresponding

\footnotetext{
${ }^{24}$ The ADL and CL models are similar in one important respect: they both assume that mortgage borrowers are risk-neutral with respect to refinancing proceeds. We are not aware of any threshold models that allow for borrower risk aversion. Risk aversion would likely reduce the refinancing threshold (since refinancing today locks in an interest saving as opposed to waiting for a potentially larger but risky saving tomorrow), which would increase our estimates of psychological refinancing costs. However, if interest rates are positively correlated with household income, it is possible that delaying refinancing would insure income risk, in which case risk aversion could increase the threshold and lower our estimates of psychological refinancing costs.
} 
mortgage rate.

Most importantly, in the CL model refinancing can only occur once, rather than multiple times. Our application of the ADL model ignores the fact that under Danish rules, a refinancing today reduces the value of future refinancing opportunities by increasing mortgage principal; but the CL model makes future refinancing impossible, and so (setting aside other differences between the two models), the difference between the CL and ADL thresholds provides an upper bound on the magnitude of this effect.

The CL model does not deliver an analytical formula for the optimal refinancing threshold, so we use numerical simulations to derive thresholds corresponding to a large number of mortgages with given parameters (including candidate psychological refinancing costs), and interpolate thresholds for other mortgages.

Online Appendix K discusses the CL model and our implementation of it in greater detail, and compares the CL and ADL refinancing thresholds in our sample. We find that the average difference between the ADL and CL thresholds is 18 basis points, the median difference is 14 basis points, the standard deviation of the difference is 35 basis points, and the interquartile range runs from -9 to 39 basis points. The CL and ADL thresholds have a cross-sectional correlation of 0.85 . Importantly, the differences between the two thresholds are large only for mortgages with lower principal and shorter maturities; these mortgages have high refinancing thresholds whose exact values are sensitive to assumptions, but for this very reason they do not play an important role in our analysis because both the CL and ADL models imply that they should not be refinanced. ${ }^{25}$

Online Appendix L replicates Table 3 and Figures 4-6 and 8 using CL thresholds in place of ADL thresholds. Online Appendix M repeats this exercise for the smaller sample of mortgages, already considered in Appendix E, that have principal value above DKK 250,000 and remaining

\footnotetext{
${ }^{25}$ Among mortgages with high principal and long maturity, the correlation between the ADL and CL thresholds is much lower. This is because such mortgages differ primarily in their exogenous termination probability, which is modeled as a constant hazard by ADL and as a shift in a known future termination date by CL. A higher termination probability raises the ADL refinancing threshold, but lowers the CL threshold by reducing the value of the option to wait for lower mortgage rates in the future. Appendix $\mathrm{K}$ discusses this phenomenon in greater detail. It does not affect our empirical results because both the ADL and CL thresholds for mortgages of this sort are small relative to the thresholds that trigger household refinancing in our data.
} 
maturity of at least 20 years. There are some shifts in the curves relating ranked variables to psychological costs of refinancing measured in DKK, but no other changes worthy of note.

\section{Reconciliation with financial advice and prompt refinancing behavior}

We complement the CL analysis with two further reality checks on the ADL refinancing threshold. First, we verify that the shape of the ADL threshold illustrated in Figure 1 is broadly consistent with the recommendations of Danish financial advisers. A typical recommendation from the real estate advisory firm Bolius Boligejernes Videncenter (see https://www.bolius.dk/omlaegning-af-ditrealkreditlaan-17799/) is to refinance when a) the difference between the old and the new coupon is at least 150 basis points, b) the outstanding principal is at least DKK 250,000, and c) the remaining time to maturity is at least 5 to 10 years. Mortgages with large outstanding principal and/or long remaining maturity are recommended to refinance at a lower coupon differential. In our sample period, the difference between the yield and the coupon on new mortgages is on average 36 basis points, implying from condition a) that refinancing is advantageous when the difference between the old coupon and the new yield is 114 basis points. In comparison the median household in our sample has an ADL threshold of 75 basis points. While this is 39 basis points lower, we note that the average mortgage in our sample has greater outstanding principal (DKK 926,000) and a longer time to maturity (23 years) than the mortgage contemplated by Bolius.

Second, we check the relationship between the empirically measured incentives of prompt refinancers and the ADL threshold. To ensure that we pick up individuals who respond promptly to incentives, we conduct this exercise for loans issued in the last quarter of 2009 or later. We do so to avoid misclassifying sluggish households from early loan cohorts as prompt refinancers during our sample period.

For each cohort of issued loans, we define individuals as prompt refinancers if they are in the first few percent of households to refinance in a given loan cohort. We vary this percentage cutoff, picking the first $2.5 \%, 5 \%$, and $10 \%$ of households to refinance. We measure the average incentive for each such household, the interest saving relative to the ADL threshold, in the first quarter in 
the time series in which the percentage cutoff is hit. ${ }^{26}$

When we average across loan cohorts using weights proportional to the number of loans issued in each cohort, we find that prompt refinancers classified with a $2.5 \%$ cutoff have a weighted average incentive of 24 basis points; the $5 \%$ cutoff yields 49 basis points, and a 10\% cutoff, 64 basis points. This simple exercise produces average incentives for prompt refinancers that are quite small, which is consistent with the ADL formula approximately capturing the rational refinancing threshold in the Danish institutional setting. Online Appendix N provides more details about this exercise.

\section{E. Functional form of the stochastic choice model}

Finally, we explore the effect of functional form misspecification on our parameter estimates. Online Appendix $\mathrm{O}$ uses a probability distortion, analogous to that used in behavioral finance models, to alter the assumed logistic distribution of the stochastic choice error. We estimate our model on data simulated from the misspecified model. We find that symmetric probability distortion has minimal effect on any of the parameters of our model, while an asymmetric distortion is picked up by our estimation procedure as an increase in the unconditional average probability that households are asleep and the unconditional average psychological refinancing cost. However, in no case does functional form misspecification have any major effect on the parameter estimates that capture cross-sectional variation in time-dependent and state-dependent inaction, which are the main concern of our paper.

\subsection{Applying the model}

In this section we use our model to explore the effects on refinancing of various plausible alterations to the mortgage system in a hypothetical simulation. We consider a random sample of mortgage

\footnotetext{
${ }^{26}$ An example might make this easier to understand. The first loan cohort that we consider has an issue date of 2009Q4 and contains 7,554 loans. In this cohort, 47 loans refinance in 2010Q1, 73 in 2010Q2, 398 in 2010Q3, 503 in 2010Q4, and so on. The first quarter in which the 5\% cutoff for prompt refinancing is exceeded is 2010Q3, in which $5.2 \%$ of all loans in the 2009Q4 cohort are refinanced. Thus, households in the 2009Q4 cohort who refinanced their mortgages in 2010Q3 are classified as "prompt" refinancers, and we calculate their average incentives in that quarter to be 8 basis points.
} 
borrowers drawn from the Danish population at the start of our refinancing sample period in the first quarter of 2010. We lower the interest rate from the actual level by 172 basis points, a decline chosen to give $90 \%$ of the sample positive refinancing incentives relative to the ADL threshold. We fix the interest rate at this low level for three years, and track refinancing behavior over time in various alternative scenarios.

As a first exercise, we calculate the effects of different components of our model on aggregate refinancing rates and the refinancing efficiency of different types of borrowers. The top panel of Online Appendix Figure B11 shows cumulative aggregate refinancing rates in a fully rational model with automatic refinancing at the ADL threshold, a pure state-dependent model with rational refinancing at the threshold augmented by our estimated psychological refinancing costs, a pure time-dependent model in which information-gathering costs lead to rational refinancing at the ADL threshold only by households that are awake, and finally our baseline model. Unsurprisingly the cumulative refinancing rate for the fully rational model reaches $90 \%$ in the first quarter and stays there, while the cumulative refinancing rate in the state-dependent model with augmented thresholds is lower at just above $60 \%$ but has the same time pattern. A pure time-dependent model, by contrast, has a smoothly rising cumulative refinancing rate, and our model has the same time pattern at a lower level.

We also calculate the refinancing rates of different groups of borrowers as a fraction of the rational refinancing rates for the same groups. This is closely related to the measure of refinancing efficiency illustrated in Figure 3, although for simplicity we do not calculate interest savings. These refinancing efficiency measures can be calculated at any period of the simulation, and Online Appendix Figure B11 reports results two years after the initial interest rate decline. Among households grouped by age, state-dependent inaction lowers the refinancing efficiency of middle-aged households relative to younger and older households, while time-dependent inaction lowers the refinancing efficiency of older households. In our full model the effect of time-dependent inaction dominates, just as we saw in the data in Figure 5. Among households grouped by income, state-dependent inaction lowers the refinancing efficiency of higher-income households, while time-dependent inaction lowers the refinancing efficiency of poorer households. Again, time-dependent inaction dominates in both 
the simulation and the data.

In Figure 10 we consider three modifications of the Danish mortgage system designed specifically to improve the refinancing efficiency of older and poorer households. These are compared with our baseline model of the current Danish mortgage system and with fully rational refinancing at the ADL threshold. The first modification (labeled R) rebates the fixed component of the mortgage refinancing fee (DKK 3,000) and removes the caps on the fees to make the mortgage refinancing fee proportional. This eliminates the tendency of smaller mortgages (which are disproportionately held by older and poorer households) to have higher ADL thresholds. The second modification advertises refinancing opportunities (lowers information-gathering costs) in such a way that onehalf of all households who were asleep are woken up. The third modification combines these two policies.

The top panel of Figure 10 shows that waking households up is a much more powerful way to increase aggregate refinancing rates. This may not be surprising given the large size of the interest rate reduction we are considering, which is sufficient to give $90 \%$ of households an incentive to refinance relative to the ADL threshold. The second and third panels similarly show that waking households up - reducing time-dependent inaction - is the best way to improve the refinancing efficiency of older and poorer households, although refinancing rebates do have a larger effect on poorer households as one would expect.

These findings are relevant for the literature on the mortgage refinancing channel of monetary transmission (Auclert 2016, Agarwal et al. 2015, Beraja et al. 2017, Di Maggio et al. 2016). Expansionary monetary policy stimulates the economy in part by lowering mortgage rates, which in turn increases household consumption. However, in a fixed-rate mortgage system lower mortgage rates relieve the budgets only of households that refinance their mortgages. Such budget relief is persistent, and therefore should stimulate consumption roughly one-for-one for households that have either no binding borrowing constraints (permanent income consumers) or fixed and binding borrowing constraints. To the extent that budget relief relaxes borrowing constraints by permitting households to extract home equity, or to increase uncollateralized borrowing, the effect on consump- 
tion may initially exceed the effect on budget relief. Refinancing failures by poorer households limit the passthrough from declining mortgage rates to consumption, and particularly do so to the extent that poorer households are more likely to face borrowing constraints that can be relaxed by budget relief. Policies to mitigate such refinancing failures - by reducing information-gathering costs or even refinancing mortgages automatically - therefore have the potential to increase the effectiveness of monetary policy stimulus during economic downturns.

\section{Conclusion}

In this paper we have documented slow mortgage refinancing behavior among Danish households. The Danish context is particularly advantageous for studying this type of household behavior because the Danish mortgage system places no restrictions on refinancing that does not involve cashout, so households that pass up opportunities to substantially reduce their mortgage costs are not constrained, but are making mistakes in managing their finances. In addition, the Danish statistical system allows us to measure the demographic and economic characteristics of households in great detail.

We distinguish between time-dependent and state-dependent models of slow refinancing. A time-dependent model has a reduced probability of refinancing at any incentive, while a statedependent model increases the threshold that triggers refinancing, equivalent to the addition of psychological costs to the direct financial costs of refinancing. We demonstrate that while a pure state-dependent model can fit any observed behavior in a single cross-section of the data, it imposes strong restrictions in a panel that are rejected in the data. We therefore build a model which allows for both sources of inaction to affect refinancing decisions.

We find that older households and those with lower education, income, housing wealth, and financial wealth are all strongly affected by time-dependent inaction, whereas the psychological refinancing costs that create state-dependent inaction are greatest for middle-aged households and those with high financial wealth. The cross-sectional variation in psychological refinancing costs 
is consistent with the view that these costs may in part capture the high value of time for certain households. Time-dependent slow refinancing is the primary reason why older households and those with lower socioeconomic status achieved low interest savings from refinancing during our sample period, relative to the savings achievable with an optimal refinancing strategy.

One might be concerned that these patterns are sensitive to the ADL formula we have used as our rational benchmark for refinancing. To address this concern, we have shown that Danish households who refinance promptly (in the first few percent of households whose old mortgages carry the same interest rate) do so at interest savings similar to the ADL threshold. We have also recomputed all thresholds using an alternative model of optimal refinancing due to Chen and Ling (1989), and obtain similar results. Our conclusion is that while different assumptions can have noticeable effects on optimal refinancing thresholds, they cannot make a large enough difference to account for the slow refinancing rates observed in the Danish data or to substantially alter the cross-sectional patterns in time- and state-dependent refinancing that we document.

Both our methodology and our findings have relevance beyond the context of this paper. We believe that the mixture model we have used to estimate time-dependent slow refinancing is a promising econometric method for estimating the prevalence of behavioral biases in the population, and a useful alternative to the competing-risks proportional hazard framework of Deng, Quigley, and Van Order (2000) for modeling heterogeneous prepayment behavior. Our findings reinforce concerns that financial capabilities deteriorate late in life (Agarwal, Driscoll, Gabaix, and Laibson 2009) and that poorer households make worse financial decisions (Campbell 2006, Calvet, Campbell, and Sodini 2009b, Badarinza, Campbell, and Ramadorai 2016), contributing to inequality of wealth (Piketty 2014, Bach, Calvet, and Sodini 2015, Campbell 2016). Finally, our results imply that the effect of expansionary monetary policy on household consumption is weakened in economies with predominantly fixed-rate mortgages, not only by barriers to refinancing that may result from low credit scores and house prices, as emphasized by Agarwal et al. (2015), Beraja et al. (2017), and Di Maggio et al. (2016), but also by the slow reaction of many households to refinancing opportunities. 


\section{References}

Abel, Andrew B., Janice C. Eberly, and Stavros Panageas, 2007, "Optimal Inattention to the Stock Market", American Economic Review: Papers and Proceedings 97, 244-249.

Abel, Andrew B., Janice C. Eberly, and Stavros Panageas, 2013, "Optimal Inattention to the Stock Market with Information Costs and Transactions Costs", Econometrica 81, 1455-1481.

Agarwal, Sumit, Gene Amromin, Souphala Chomsisengphet, Tomasz Piskorski, Amit Seru, and Vincent Yao, 2015, "Mortgage Refinancing, Consumer Spending and Competition: Evidence from the Home Affordable Refinancing Program", NBER Working Paper 21512.

Agarwal, Sumit, John Driscoll, and David Laibson, 2013, "Optimal Mortgage Refinancing: A Closed Form Solution", Journal of Money, Credit, and Banking 45, 591-622.

Agarwal, Sumit, John Driscoll, Xavier Gabaix, and David Laibson, 2009, "The Age of Reason: Financial Decisions Over the Life Cycle and Implications for Regulation", Brookings Papers on Economic Activity 2, 51-101.

Agarwal, Sumit, Richard J. Rosen, and Vincent Yao, 2016, "Why Do Borrowers Make Mortgage Refinancing Mistakes?", Management Science 62, 3494-3509.

Agnew, Julie, Pierluigi Balduzzi, and Annika Sunden, 2003, "Portfolio Choice and Trading in a Large 401(k) Plan", American Economic Review 93, 193-215.

Alvarez, Fernando, Luigi Guiso, and Francesco Lippi, 2012, "Durable Consumption and Asset Management with Transaction and Observation Costs", American Economic Review 102, $2272-2300$.

Alvarez, Fernando, Francesco Lippi, and Luigi Paciello, 2011, "Optimal Price Setting With Observation and Menu Costs", Quarterly Journal of Economics 126, 1909-1960.

Anagol, Santosh, Vimal Balasubramaniam, and Tarun Ramadorai, 2018, "Endowment Effects in the Field: Evidence from India's IPO Lotteries", forthcoming Review of Economic Studies.

Andersen, Steffen, John Y. Campbell, Kasper Meisner Nielsen, and Tarun Ramadorai, 2019, "Appendix to Sources of Inaction in Household Finance", available online at authors' websites.

Archer, Wayne R., David C. Ling, and Gary A. McGill, 1996, "The Effect of Income and Collateral Constraints on Residential Mortgage Terminations", Regional Science and Urban Economics $26,235-261$.

Auclert, Adrien, 2016, "Monetary Policy and the Redistribution Channel", unpublished paper, Stanford University.

Bach, Laurent, Laurent E. Calvet, and Paolo Sodini, 2015, "Rich Pickings? Risk, Return, and Skill in the Portfolios of the Wealthy", unpublished paper, Swedish House of Finance, EDHEC Business School, and Stockholm School of Economics. 
Badarinza, Cristian, John Y. Campbell, and Tarun Ramadorai, 2016, "International Comparative Household Finance", Annual Review of Economics 8, 111-144.

Badarinza, Cristian, John Y. Campbell, and Tarun Ramadorai, 2017, "What Calls to ARMs? International Evidence on Interest Rates and the Choice of Adjustable Rate Mortgages," forthcoming Management Science.

Bajo, Emanuele and Massimiliano Barbi, 2016, "Out of Sight, Out of Mind: Media Coverage, Financial Literacy, and Mortgage Refinancing", unpublished paper, University of Bologna.

Bennett, Paul, Richard Peach, and Stavros Peristiani, 2001, "Structural Change in the Mortgage Market and the Propensity to Refinance", Journal of Money, Credit, and Banking 33, 955975.

Beraja, Martin, Andreas Fuster, Erik Hurst, and Joseph Vavra, 2017, "Regional Heterogeneity and Monetary Policy", NBER Working Paper 23270.

Bhutta, Neil, Andreas Fuster, and Aurel Hizmo, 2018, "Paying Too Much? Price Dispersion in the US Mortgage Market", unpublished paper, Federal Reserve Board and Swiss National Bank.

Bhutta, Neil and Benjamin J. Keys, 2016, "Interest Rates and Equity Extraction During the Housing Boom", American Economic Review 106, 1742-1774.

Bilias, Yannis, Dimitris Georgarakos, and Michael Haliassos, 2010, "Portfolio Inertia and Stock Market Fluctuations", Journal of Money, Credit and Banking 42, 715-742.

Brueckner, Jan K. and James R. Follain, 1988, "The Rise and Fall of the ARM: An Econometric Analysis of Mortgage Choice," Review of Economics and Statistics 70, 93-102.

Brunnermeier, Markus K. and Stefan Nagel, 2008, "Do Wealth Fluctuations Generate TimeVarying Risk Aversion? Micro-Evidence on Individuals", American Economic Review 98, $713-736$.

Bucks, Brian and Karen Pence, 2008, "Do Borrowers Know Their Mortgage Terms?", Journal of Urban Economics 64, 218-233.

Caballero, Ricardo J. and Eduardo M. Engel, 1991, "Dynamic (S,s) Economics", Econometrica $59,1659-1686$.

Calvet, Laurent, John Y. Campbell, and Paolo Sodini, 2009a, "Fight or Flight? Portfolio Rebalancing by Individual Investors", Quarterly Journal of Economics 124, 301-348.

Calvet, Laurent, John Y. Campbell, and Paolo Sodini, 2009b, "Measuring the Financial Sophistication of Households", American Economic Review Papers and Proceedings 99, 393-398.

Calvo, Guillermo A., 1983, "Staggered Prices in a Utility-Maximizing Framework", Journal of Monetary Economics 12, 383-398. 
Cameron, A. Colin, and Trivedi, Pravin K., 2005, Microeconometrics: Methods and Applications, Cambridge University Press, New York, NY.

Campbell, John Y., 2006, "Household Finance", Journal of Finance 61, 1553-1604.

Campbell, John Y., 2013, "Mortgage Market Design", Review of Finance 17, 1-33.

Campbell, John Y., 2016, "Restoring Rational Choice: The Challenge of Consumer Financial Regulation", American Economic Review: Papers and Proceedings 106(5):1-30.

Campbell, John Y. and Joao Cocco, 2003, "Household Risk Management and Optimal Mortgage Choice", Quarterly Journal of Economics 118, 1449-1494.

Campbell, John Y. and Joao Cocco, 2015, "A Model of Mortgage Default", Journal of Finance 70, 1495-1554.

Caplin, Andrew, 2016, "Measuring and Modeling Attention", Annual Review of Economics 8, 379-403.

Caplin, Andrew, Charles Freeman, and Joseph Tracy, 1997, "Collateral Damage: Refinancing Constraints and Regional Recessions", Journal of Money, Credit, and Banking 29, 496-516.

Caplin, Andrew and John Leahy, 1991, "State-Dependent Pricing and the Dynamics of Money and Output", Quarterly Journal of Economics 106, 683-708.

Caplin, Andrew and Daniel F. Spulber, 1987, "Menu Costs and the Neutrality of Money", Quarterly Journal of Economics 102, 703-725.

Chen, Andrew and David Ling, 1989, "Optimal Mortgage Refinancing with Stochastic Interest Rates", AREUEA Journal 17, 278-99.

Chen, Hui, Michael Michaux, and Nikolai Roussanov, 2013, "Houses as ATMs? Mortgage Refinancing and Macroeconomic Uncertainty", unpublished paper, MIT, USC, and University of Pennsylvania.

Choi, James J., David Laibson, Brigitte Madrian, and Andrew Metrick, 2002, "Defined Contribution Pensions: Plan Rules, Participant Decisions, and the Path of Least Resistance", in James Poterba ed. Tax Policy and the Economy 16, 67-113.

Choi, James J., David Laibson, Brigitte Madrian, and Andrew Metrick, 2004, "For Better or for Worse: Default Effects and 401(k) Savings Behavior", in David Wise ed. Perspectives on the Economics of Aging, University of Chicago Press.

DellaVigna, Stefano, and Joshua M. Pollet, 2007, "Demographics and Industry Returns", American Economic Review 97, 1667-1702.

Deng, Yongheng and John M. Quigley, 2012, "Woodhead Behavior and the Pricing of Residential Mortgages", unpublished paper, National University of Singapore and University of California Berkeley. 
Deng, Yongheng, John M. Quigley and Robert Van Order, 2000, "Mortgage Terminations, Heterogeneity, and the Exercise of Mortgage Options", Econometrica 68, 275-307.

Dhillon, Upinder S., James D. Shilling, and C.F. Sirmans, 1987, "Choosing Between Fixed and Adjustable Rate Mortgages: Note", Journal of Money, Credit, and Banking 19, 260-267.

Di Maggio, Marco, Amir Kermani, Benjamin Keys, Tomasz Piskorski, Rodney Ramcharan, Amit Seru, and Vincent Yao, 2016, "Monetary Policy Pass-Through: Mortgage Rates, Household Consumption and Voluntary Deleveraging", forthcoming American Economic Review.

Duffie, Darrell, and Tong-sheng Sun, 1990, "Transactions Costs and Portfolio Choice in a DiscreteContinuous-Time Setting", Journal of Economic Dynamics and Control 14, 35-51.

El-Gamal, Mahmoud A. and David M. Grether, 1995, "Are People Bayesian? Uncovering Behavioral Strategies", Journal of the American Statistical Association 90, 1137-1145.

Gabaix, Xavier, Arvind Krishnamurthy, and Olivier Vigneron, 2007, "Limits of Arbitrage: Theory and Evidence from the Mortgage-Backed Securities Market", Journal of Finance 62, 557-595.

Gabaix, Xavier and David I. Laibson, 2002, "The 6D Bias and the Equity-Premium Puzzle," in Ben S. Bernanke and Kenneth S. Rogoff eds. NBER Macroeconomics Annual 2001, MIT Press, Cambridge, MA, 257-312.

Gaudecker, Hans-Martin von, Arthur van Soest, and Erik Wengstrom, 2011, "Heterogeneity in Risky Choice Behavior in a Broad Population", American Economic Review 101, 664-694.

Gouriéroux, Christian, and Monfort, Alain, 1996, Statistics and Econometric Models, Cambridge University Press, Cambridge, UK.

Gyntelberg, J., Kjeldsen, K., Baekmand Nielsen, M., and Persson, M., 2012, "The 2008 Financial Crisis and the Danish Mortgage Market", in A. Bardhan, R.H. Edelstein, and C.A. Kroll eds. Global Housing Markets: Crises, Policies, and Institutions, John Wiley, 53-68.

Haliassos, Michael, Thomas Jansson, and Yigitcan Karabulut, 2019, "Financial Literacy Externalities," forthcoming Review of Financial Studies.

Hall, Arden, 2000, "Controlling for Burnout in Estimating Mortgage Prepayment Models", Journal of Housing Economics 9, 215-232.

Handel, Benjamin R., 2013, "Adverse Selection and Inertia in Health Insurance Markets: When Nudging Hurts", American Economic Review 103, 2643-2682.

Johnson, Kathleen W. and Geng Li, 2014, "Are Adjustable-Rate Mortgage Borrowers Borrowing Constrained?," Real Estate Economics 42, 457-471.

Harrison, Glenn W. and E. Elisabet Rutström, 2009, "Expected Utility Theory and Prospect Theory: One Wedding and a Decent Funeral," Experimental Economics 12, 133-158. 
Johnson, Eric, Stephan Meier, and Olivier Toubia, 2015, "Leaving Money on the Kitchen Table: Exploring Sluggish Mortgage Refinancing Using Administrative Data, Surveys, and Field Experiments", unpublished paper, Columbia Business School.

Kang, Pan and Stavros A. Zenios, 1992, "Complete Prepayment Models for MBS", Management Science 38, 1665-1685.

Keys, Benjamin J., Devin G. Pope, and Jaren C. Pope, 2016, "Failure to Refinance", Journal of Financial Economics 122, 482-499.

Khandani, Amir E., Andrew W. Lo, and Robert C. Merton, 2013, "Systemic Risk and the Refinancing Ratchet Effect", Journal of Financial Economics 108, 29-45.

Koijen, Ralph S.J., Van Hemert, Otto and Stijn Van Nieuwerburgh, 2009, "Mortgage Timing," Journal of Financial Economics 93, 292-324.

LaCour-Little, Michael, 1999, "Another Look at the Role of Borrower Characteristics in Predicting Mortgage Prepayments", Journal of Housing Research 10, 45-60.

Laibson, David, 1997, "Golden Eggs and Hyperbolic Discounting", Quarterly Journal of Economics $112,443-478$.

Lea, M., 2011, "Alternative Forms of Mortgage Finance: What Can We Learn from Other Countries?" in N. Retsinas and E. Belsky eds., Moving Forward: The Future of Consumer Credit and Mortgage Finance, Joint Center for Housing Studies, Harvard University, Cambridge, MA, and Brookings Institution Press, Washington, DC, 118-149.

Luce, R. Duncan, 1959, Individual Choice Behavior: A Theoretical Analysis, Wiley, New York, NY.

Madrian, Brigitte and Dennis Shea, 2001, "The Power of Suggestion: Inertia in 401(k) Participation and Savings Behavior", Quarterly Journal of Economics 66, 1149-1188.

Matějka, Filip and Alisdair McKay, 2015, "Rational Inattention to Discrete Choices: A New Foundation for the Multinomial Logit Model", American Economic Review 105, 272-298.

Maturana, Gonzalo and Jordan Nickerson, 2017, "Teachers Teaching Teachers: The Role of Networks on Financial Decisions", unpublished paper, Emory University and Boston College.

McConnell, John J., and Manoj Singh, 1994, "Rational Prepayments and the Valuation of Collateralized Mortgage Obligations", Journal of Finance 49, 891-921.

McLachlan, Geoffrey and David Peel, 2000, Finite mixture models, Wiley, New York, NY.

Miles, David, 2004, The UK Mortgage Market: Taking a Longer-term View, HM Treasury, London, UK. 
Moscarini, Giuseppe, 2004, "Limited Information Capacity as a Source of Inertia", Journal of Economic Dynamics and Control 28, 2003-2035.

Nakamura, Emi, and Jon Steinsson, 2010, "Monetary Non-Neutrality in a Multisector Menu Cost Model", Quarterly Journal of Economics 125, 961-1013.

O'Donoghue, Ted, and Matthew Rabin, 1999, "Doing it Now or Later", American Economic Review 89, 103-124.

Pearson, Karl, 1894, "Contributions to the Mathematical Theory of Evolution", Philosophical Transactions of the Royal Society of London A, 71-110.

Piketty, Thomas, 2014, Capital in the 21st Century, Harvard University Press, Cambridge, MA.

Reis, Ricardo, 2006a, "Inattentive Consumers", Journal of Monetary Economics 53, 1761-1800.

Reis, Ricardo, 2006b, "Inattentive Producers", Review of Economic Studies 73, 793-821.

Schwartz, Allie, 2006, "Household Refinancing Behavior in Fixed-Rate Mortgages", unpublished paper, Harvard University.

Schwartz, Eduardo S., and Walter N. Torous, 1989, "Prepayment and the Valuation of MortgageBacked Securities", Journal of Finance 44, 375-392.

Sims, Christopher A., 2003, "Implications of Rational Inattention", Journal of Monetary Economics 50, 665-690.

Stanton, Richard, 1995, "Rational Prepayment and the Valuation of Mortgage-Backed Securities", Review of Financial Studies 8, 677-708.

Taylor, John B., 1980, "Aggregate Dynamics and Staggered Contracts", Journal of Political Economy $88,1-23$.

Tracy, Joseph and Joshua Wright, 2012, "Payment Changes and Default Risk: The Impact of Refinancing on Expected Credit Losses", Federal Reserve Bank of New York Staff Report No. 562 .

Train, Kenneth E., 2009, Discrete Choice Methods with Simulation, Cambridge University Press, New York, NY.

Veldkamp, Laura, 2011, Information Choice in Macroeconomics and Finance, Princeton University Press, Princeton, NJ.

Veronesi, Pietro, 2010, Fixed Income Securities: Valuation, Risk, and Risk Management, John Wiley \& Sons, Hoboken, NJ.

Woodford, Michael, 2009, "Information-Constrained State-Dependent Pricing", Journal of Monetary Economics 56, Supplement, S100-S124. 
Woodward, Susan E., and Robert E. Hall, 2010, "Consumer Confusion in the Mortgage Market: Evidence of Less Than a Perfectly Transparent and Competitive Market", American Economic Review 100, 511-515.

Woodward, Susan E. and Robert E. Hall, 2012, "Diagnosing Consumer Confusion and Sub-Optimal Shopping Effort: Theory and Mortgage Market Evidence", American Economic Review 102, 3249-3276.

Zandi, Mark and Cristian deRitis, 2011, "Improved HARP Will Expand Refinancing, Boost Recovery", unpublished report, Moody's Analytics.

Zhu, Jun, 2012, "Refinance and Mortgage Default: An Empirical Analysis of the HARP's Impact on Default Rates", unpublished paper, Freddie Mac. 


\section{Table 1: Characteristics of Danish Fixed Rate Mortgages}

These statistics are calculated using all unique mortgages taken by households in Denmark with an unchanging number of adult members, and with a single fixed rate mortgage. In Panel A, the rows show, in order, the total number of household-quarter observations in the data; the average principal remaining (outstanding) on these mortgages in millions of Danish Kroner (DKK); the average number of years remaining before mortgages mature; the average loan-to-value (LTV) ratio on these mortgages; the fraction refinancing in a quarter (i.e., the fraction of households that refinanced their pre-existing mortgage voluntarily rather than refinancing for exogenous reasons such as moving house); the fraction refinancing from a fixed rate mortgage (FRM) to another FRM; the fraction of all mortgages with negative refinancing incentives calculated using Agarwal et al. (2013) formula (ADL); the fraction of mortgages with negative ADL incentives which refinance; the fraction of mortgages with positive refinancing incentives computed using the ADL formula; and the fraction with positive ADL incentives which refinance. In Panel B, the rows document the fractions of households refinancing either once or multiple times during the sample period. The columns document the fractions of these households refinancing at incentives which are either greater than, or less than or equal to, incentive levels previously experienced over the sample period.

Panel A: Household quarter observations

\begin{tabular}{lr}
\hline Number of observations & $9,351,183$ \\
Principal remaining (million DKK) & 0.983 \\
Years remaining on mortgage & 23.226 \\
Loan-to-value (LTV) ratio & 0.600 \\
& \\
Fraction refinancing & 0.040 \\
Fixed rate to fixed rate refinancing & 0.701 \\
Fraction with negative ADL incentive & 0.563 \\
- of which refinance & 0.013 \\
Fraction with positive ADL incentive & 0.437 \\
- of which refinance & 0.076
\end{tabular}

Panel B: Household observations

\begin{tabular}{lrrr}
\hline & All & $\begin{array}{c}\text { At higher } \\
\text { incentives }\end{array}$ & $\begin{array}{c}\text { At lower } \\
\text { incentives }\end{array}$ \\
Number of households & 614,811 & & \\
- fraction never refinancing & 0.498 & & \\
- fraction refinancing once & 0.402 & 0.276 & 0.126 \\
- fraction refinancing twice & 0.089 & 0.040 & 0.049 \\
- fraction refinancing three or more times & 0.011 & 0.002 & 0.009
\end{tabular}




\section{Table 2: Choice Models}

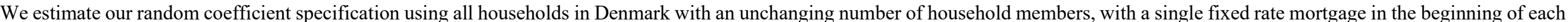

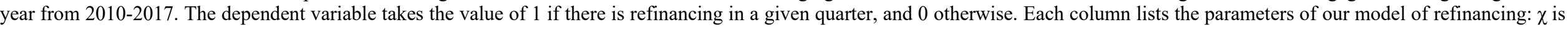

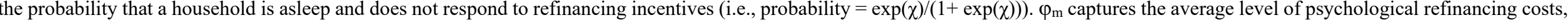

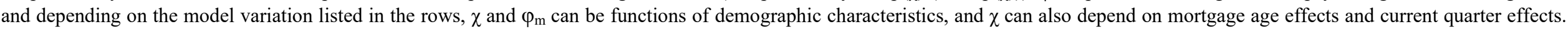

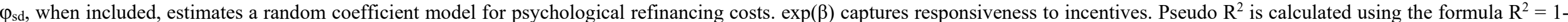

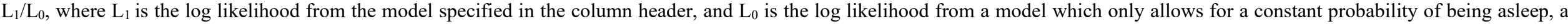
stochastic choice error, and a constant fixed psychological refinancing cost (i.e., Model 4). All coefficients in the table are significant at the $1 \%$ level or less.

\begin{tabular}{|c|c|c|c|c|c|c|c|c|c|c|}
\hline Model 1 & Model 2 & Model 3 & Model 4 & Model 5 & Model 6 & Model 7 & Model 8 & Model 9 & Model 10 & Model 11 \\
\hline-1.350 & -1.063 & 1.298 & 0.745 & 0.846 & 0.655 & 0.667 & 0.677 & 0.770 & 0.820 & 0.873 \\
\hline & $\begin{array}{c}6.126 \\
\text { No } \\
\text { No }\end{array}$ & & $\begin{array}{c}2.437 \\
\text { No } \\
\text { No }\end{array}$ & $\begin{array}{c}3.289 \\
\text { No } \\
\text { No }\end{array}$ & $\begin{array}{c}3.149 \\
\text { Yes } \\
\text { No }\end{array}$ & $\begin{array}{c}3.785 \\
\text { Yes } \\
\text { Yes }\end{array}$ & $\begin{array}{c}2.465 \\
\text { No } \\
\text { No }\end{array}$ & $\begin{array}{c}2.219 \\
\text { No } \\
\text { No }\end{array}$ & $\begin{array}{c}2.547 \\
\text { No } \\
\text { No }\end{array}$ & $\begin{array}{c}2.580 \\
\text { No } \\
\text { No }\end{array}$ \\
\hline & No & & No & No & No & No & No & No & Yes & Yes \\
\hline & & & & 1.300 & & & & & & 0.848 \\
\hline & & $\begin{array}{c}2.381 \\
\text { No } \\
\text { No } \\
\text { No }\end{array}$ & $\begin{array}{c}1.671 \\
\text { No } \\
\text { No } \\
\text { No }\end{array}$ & $\begin{array}{c}0.967 \\
\text { No } \\
\text { No } \\
\text { No }\end{array}$ & $\begin{array}{c}1.387 \\
\text { No } \\
\text { No } \\
\text { No }\end{array}$ & $\begin{array}{c}1.392 \\
\text { No } \\
\text { No } \\
\text { No }\end{array}$ & $\begin{array}{c}2.238 \\
\text { Yes } \\
\text { No } \\
\text { No }\end{array}$ & $\begin{array}{c}3.049 \\
\text { Yes } \\
\text { Yes } \\
\text { No }\end{array}$ & $\begin{array}{c}3.059 \\
\text { Yes } \\
\text { Yes } \\
\text { Yes }\end{array}$ & $\begin{array}{c}2.988 \\
\text { Yes } \\
\text { Yes } \\
\text { Yes }\end{array}$ \\
\hline-3.508 & -0.096 & -0.019 & 0.000 & 0.007 & 0.029 & 0.035 & 0.041 & 0.052 & 0.069 & 0.070 \\
\hline
\end{tabular}

- Current quarter dummies

- Mortgage age dummies

- Demographics

$\varphi_{\text {sd }}$

- Current quarter dummies

- Mortgage age dummies

- Demographics

Pseudo $\mathrm{R}^{2}$
$-3.508$
$-0.019$
0.007
0.035
0.052
0.070 


\section{Table 3: Model with Heterogenous Household Characteristics}

We estimate this specification using all households in Denmark with an unchanging number of household members, with a single fixed rate mortgage in the beginning of each year from 2010-2017. The dependent variable takes the value of 1 for a refinancing in a given quarter, and 0 otherwise. Each column lists the parameters of our model of refinancing: $\chi$ is the probability that a household is asleep and does not respond to refinancing incentives, and the rows show its dependence on the listed demographic characteristics. $\varphi$ captures the level of psychological refinancing costs (i.e., costs $=\exp (\varphi)$ ) once again as a function of demographic characteristics, and $\exp (\beta)$, which does not depend on demographics, captures the responsiveness to the incentives. The coefficients include non-linear transformations, $\mathrm{f}(\mathrm{x})$, of all the ranked control variables in addition to their levels, where $\mathrm{f}(\mathrm{x})=\sqrt{2} x^{2}$. Pseudo $\mathrm{R}^{2}$ is calculated using the formula $\mathrm{R}^{2}=1-\mathrm{L}_{1} / \mathrm{L}_{0}$, where $\mathrm{L}_{1}$ is the $\log$ likelihood from the given model and $\mathrm{L}_{0}$ is the $\log$ likelihood from a model which only allows for a constant probability of being asleep. ${ }^{* * *},{ }^{* *}$, and $^{*}$ indicate coefficients that are significant at the one, five, and ten percent level, respectively, using standard errors clustered at the level of households.

Intercept

Random coefficient component

Single male household

Single female household

Married household

Children in family

Immigrant

Financially literate

Family financially literate

Getting married

Having children

Region of Northern Jutland

Region of Middle Jutland

Region of Southern Denmark

Region of Zealand

Demeaned rank of:

Age

Length of education

Income

Financial wealth

Housing wealth

Non-linear transformation $f(x), x$ is the demeaned rank of:

Age

Length of education

Income

Financial wealth

Housing wealth

Current quarter dummies

Mortgage age dummies

Pseudo $\mathrm{R}^{2}$

Log likelihood

Observations

\begin{tabular}{ccc}
$\beta$ & $\varphi$ & $\chi$ \\
\hline $0.820^{* * *}$ & $2.547^{* * *}$ & $3.059^{* * *}$
\end{tabular}

$\begin{array}{ll}-0.088^{* * *} & 0.008 \\ -0.106^{* * *} & -0.107^{* * *} \\ 0.101^{* * *} & -0.039^{* * *} \\ 0.112^{* * *} & 0.101^{* * *} \\ -0.101^{* * *} & 0.163^{* * *} \\ -0.160^{* * *} & -0.018 \\ -0.001 & -0.093^{* * *} \\ -0.248^{* * *} & -0.070^{* * *} \\ -0.106^{* * *} & -0.087^{* * *} \\ 0.112^{* * *} & -0.280^{* * *} \\ 0.082^{* * *} & -0.215^{* * *} \\ 0.024 & -0.100^{* * *} \\ 0.064^{* * *} & 0.142^{* * *}\end{array}$

$-0.094^{* * *} \quad 0.783^{* * *}$

$0.110^{* * *} \quad-0.251^{* * *}$

$0.815^{* * *} \quad-0.763^{* * *}$

$0.906^{* * *} \quad-0.242^{* * *}$

$0.636^{* * *}-0.814^{* * *}$

$-1.323^{* * *} \quad-0.014$

$0.275^{* * *} \quad-0.005$

$-0.401^{* * *} \quad 0.615^{* * *}$

$-0.896^{* * *} \quad 0.150^{* * *}$

$-0.546^{* * *} \quad 0.380^{* * *}$

Yes

Yes

0.069

$-1,332,195$

$9,351,183$ 


\section{Figure 1: ADL Threshold as a Function of Fixed Costs}

This figure plots the ADL threshold level in basis points associated with each fixed cost in DKK on the x-axis. The solid line in the plot shows this mapping when the ADL threshold is computed using the mean estimated mortgage termination probability, the mean remaining mortgage principal, the mean remaining horizon on the mortgage, the mean interest rate on the mortgage, and the mean inflation rate. The two dashed lines in the plot show this mapping for (i) a smaller mortgage that is half the mean principal, and (ii) a shorter duration mortgage with half the mean remaining horizon to maturity.

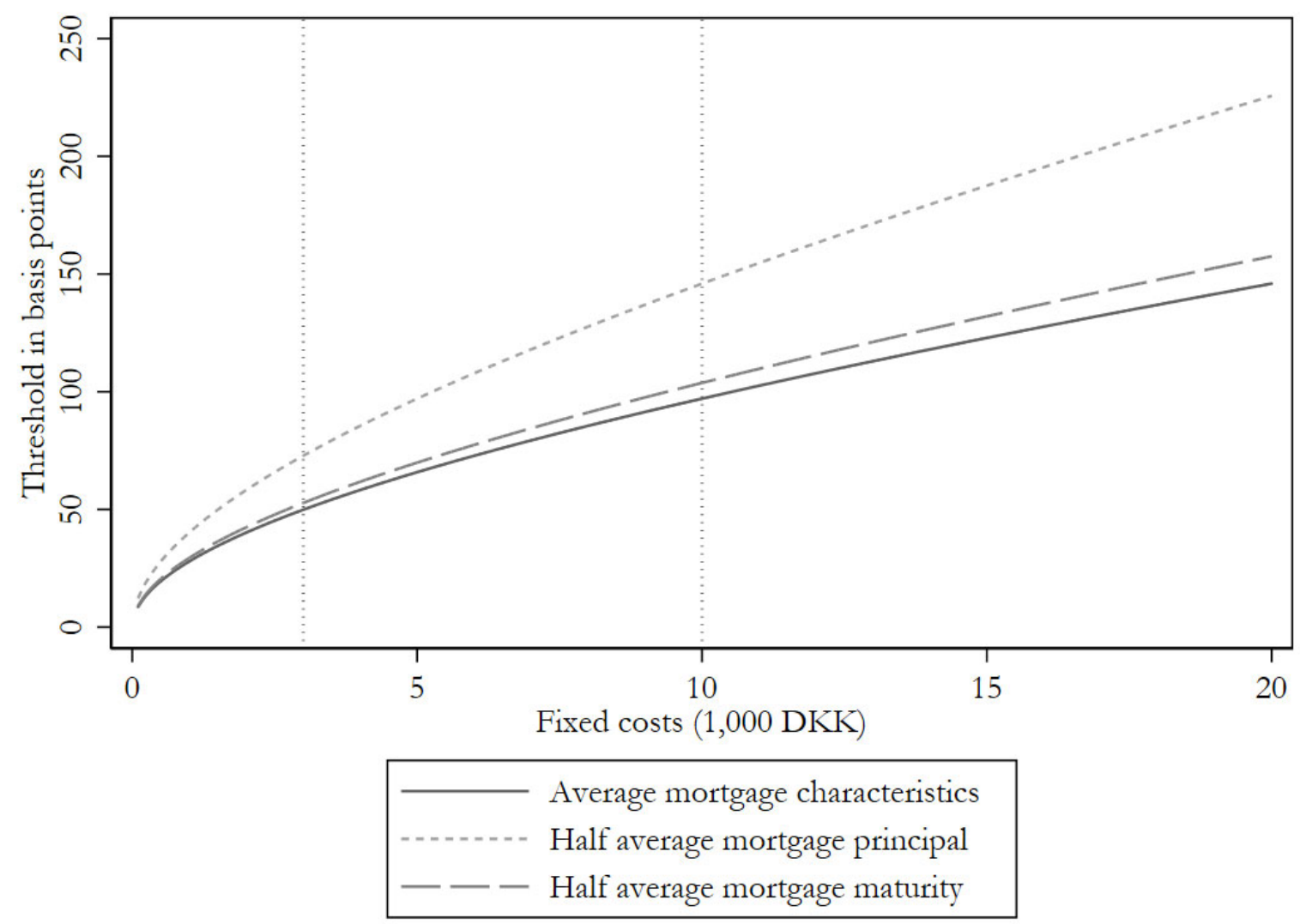




\section{Figure 2: Evaluating Refinancing Activity relative to the ADL threshold}

This figure illustrates refinancing activity in the sample evaluated against the household-quarter-specific ADL threshold. The top plot shows the histogram of computed incentives with the refinancing probability superimposed on it; the second plot shows the number of refinancings at each point corresponding to the dark line on the top plot; and the third plot shows the Kaplan-Meier "survival" (i.e., non-refinancing) estimate, i.e., plotting the number of quarters at which the household has positive incentives but does not refinance, accounting for data censoring.
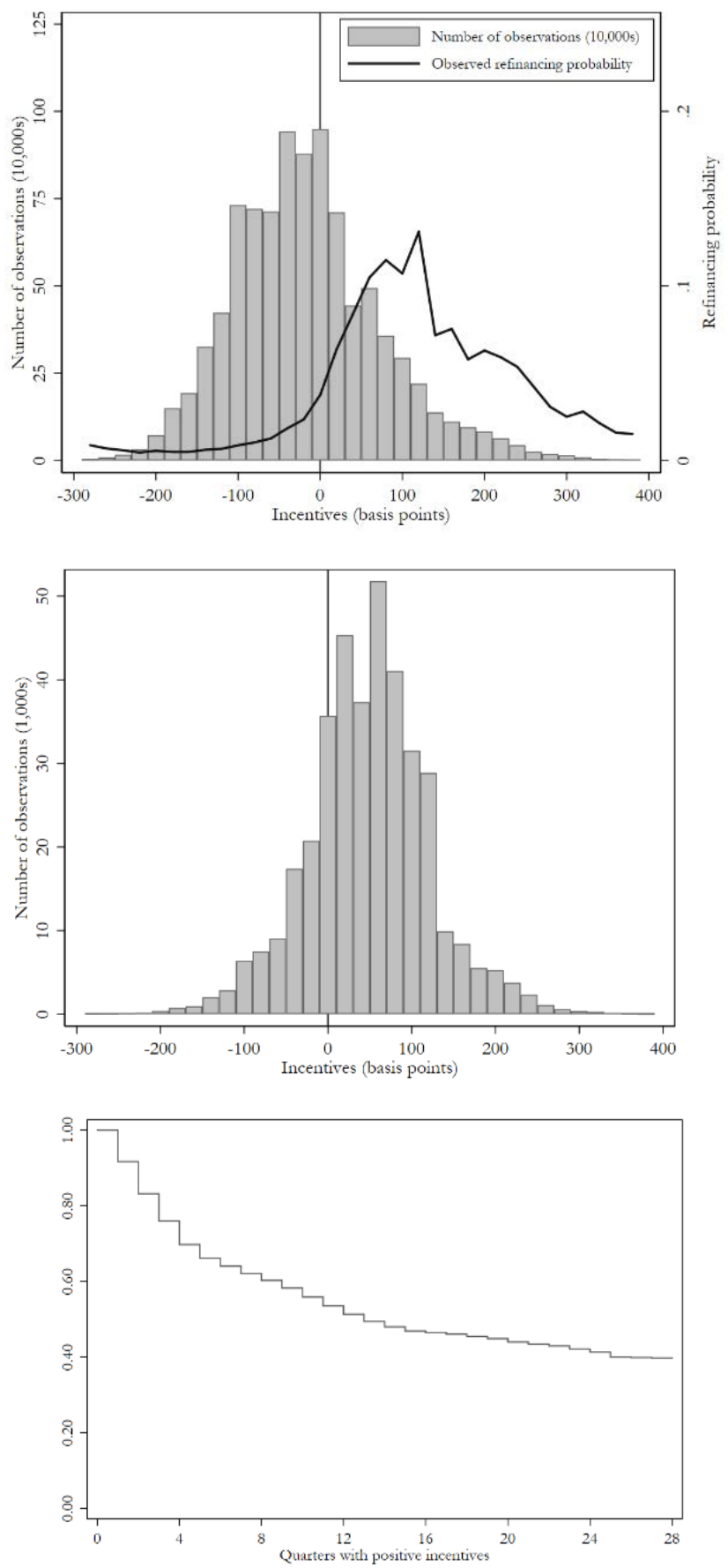


\section{Figure 3: Refinancing Activity by pre-existing Mortgage Coupon Rates}

This figure illustrates the history of refinancing activity in the sample of Danish fixed-rate mortgages. In the top plot, the bars represent the number of refinancing households in each quarter. The bars are shaded according to the coupon rate on the old mortgage from which households refinance. In the bottom plot, we show the evolution of the quarterly Danish mortgage interest rate as it moves through the average refinancing threshold for mortgages with a specific coupon rate. For example, the very top lightest shaded horizontal line in the bottom plot shows the average interest rate refinancing threshold for the group of mortgages that bear coupon rates of $6 \%$, i.e., the point at which the current interest rate needs to be, on average, to optimally justify refinancing for this group of mortgage holders. The thresholds for mortgages with coupons of $6 \%, 5 \%, 4 \%, 3.5 \%, 3 \%$, and $2.5 \%$ are $5.06 \%$, $4.22 \%, 3.27 \%, 2.83 \%, 2.28 \%$, and $1.83 \%$ respectively.
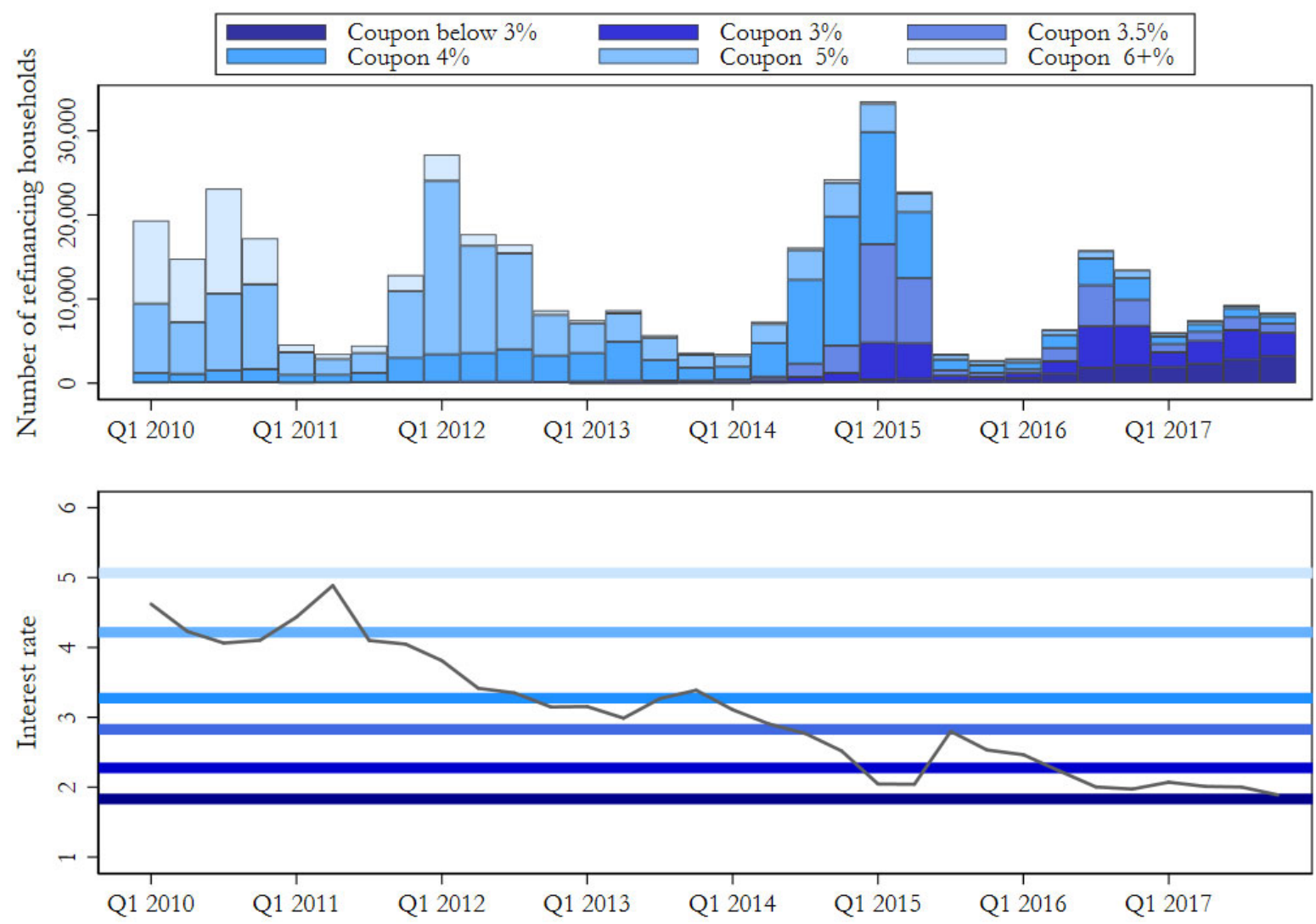


\section{Figure 4: Evaluating whether Refinancing Activity occurs at a Household-specific Threshold}

This figure illustrates refinancing activity to check whether households have idiosyncratic thresholds at which they always refinance. The top plot shows the histogram of the difference between computed incentives at the point at which households refinance and the best ever incentive experienced over the sample period prior to the point of refinancing; the second plot focuses on households that refinance at least twice, and plots the histogram across these households of the difference between the incentives at the two refinancing points; and the third plot shows the Kaplan-Meier "survival" (i.e., non-refinancing) estimate, i.e., plotting the number of quarters at which the household has incentives above those which they previously refinanced at but do not subsequently refinance, accounting for data censoring.
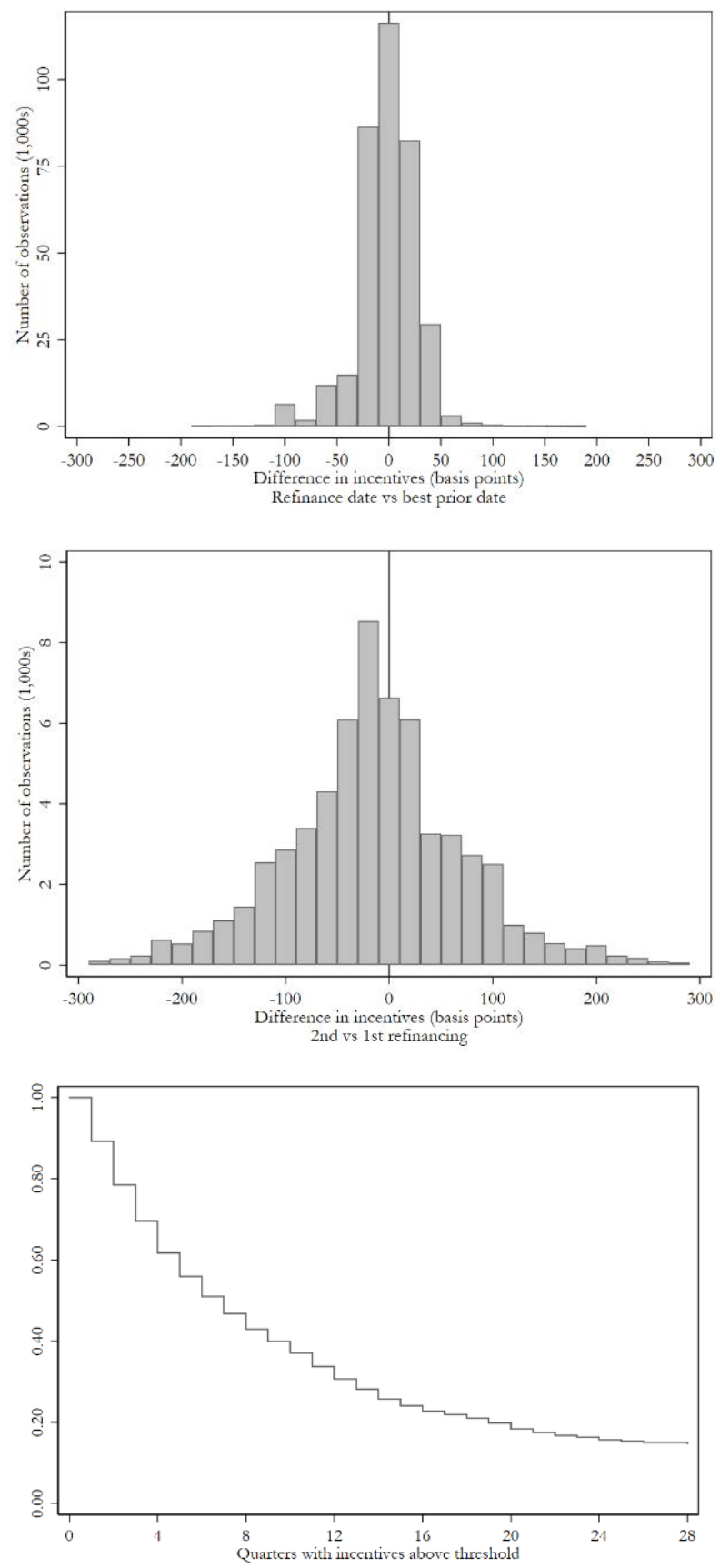


\section{Figure 5: Refinancing Efficiency}

This figure plots the average refinancing efficiency, calculated as the ratio of actual savings to counterfactual savings (counterfactual estimated under optimal refinancing), as a function of the ranked variables of age, education, income, financial wealth and housing wealth.

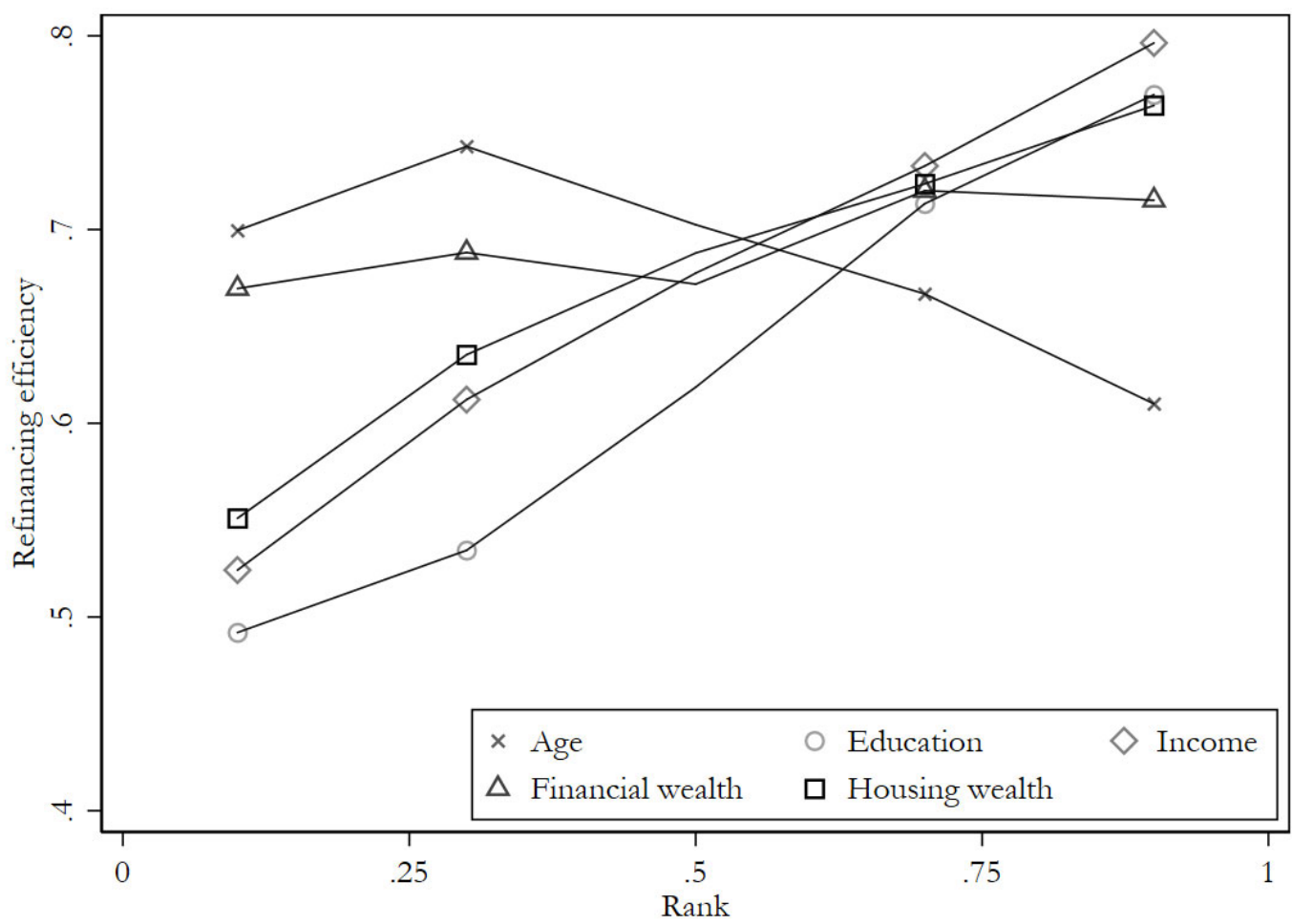


Figure 6: Refinancing, Incentives and Model Implied Refinancing Probabilities.

This figure plots refinancing probabilities from the baseline model presented in Table 3, as a function of refinancing incentives, alongside the number of observations at each level of incentives. The bars in this figure show the number of household-quarters (scale on the left vertical axis) and the lines show the fraction of these household-quarters that refinance (scale on the right vertical axis), both plotted for each level of refinancing incentives shown on the horizontal axis. The bars are 20-basis-point incentive intervals centered at the points on the horizontal axis. The solid line shows the actual refinancing probability observed in the data, the long-dashed line shows the model-predicted refinancing probability, and the short-dashed line shows the fraction of households that the model estimates do not perceive incentives (i.e., time-dependent inaction) in each period.

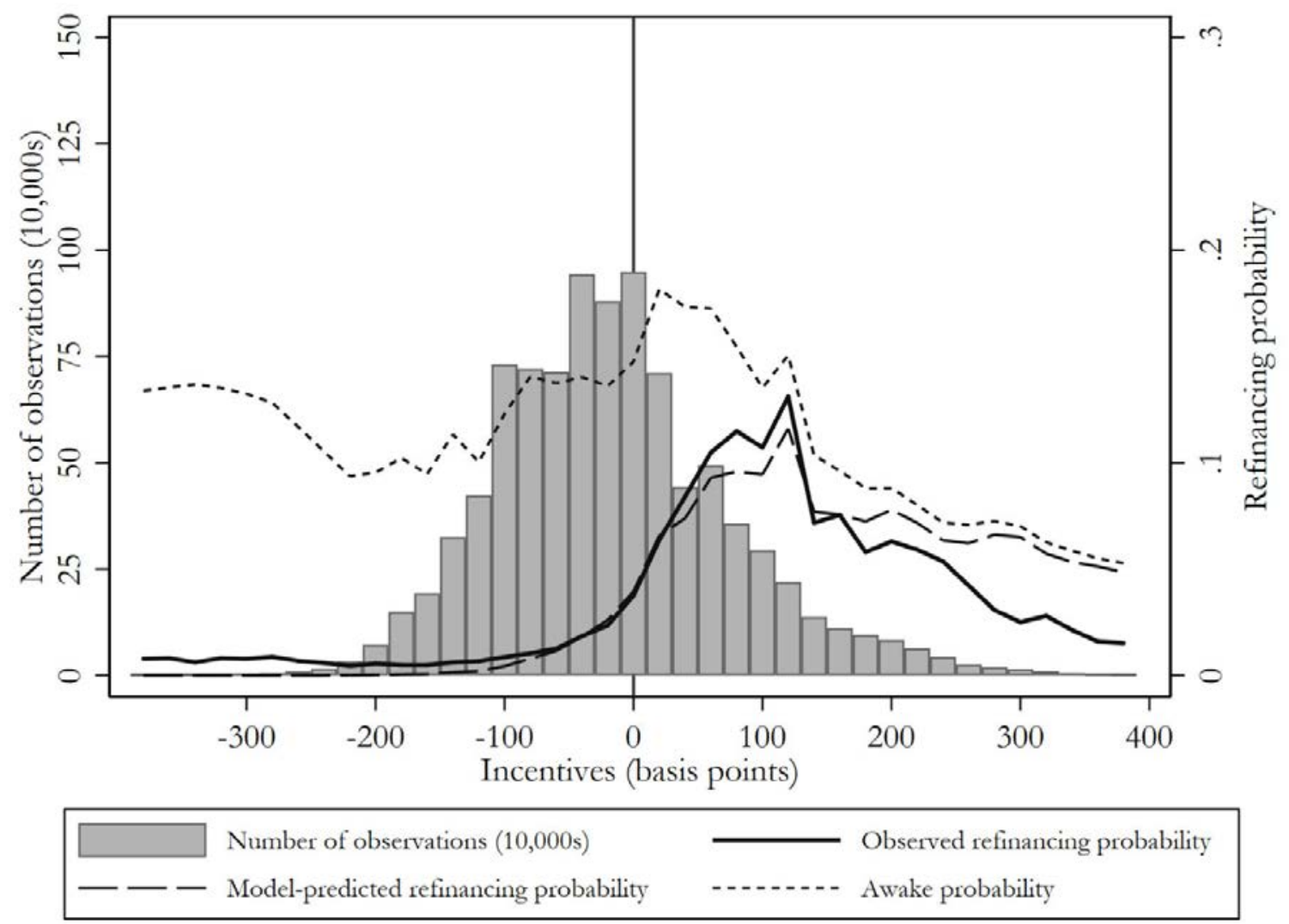




\section{Figure 7: Refinancing Cost Components}

These figures summarize the costs of refinancing estimated from the baseline model presented in Table 3 over the entire sample period. The three plots in the left column show the costs in 1,000 DKK, while the three plots in the right column show these costs in the form of the implied interest rate threshold in basis points that they translate into using the ADL (2013) function. Descending vertically, the first row shows the pure financial costs of refinancing, which are based on mortgage size. The second row shows the estimated psychological costs of refinancing, while the third row is the total costs, which sum the two rows above it.
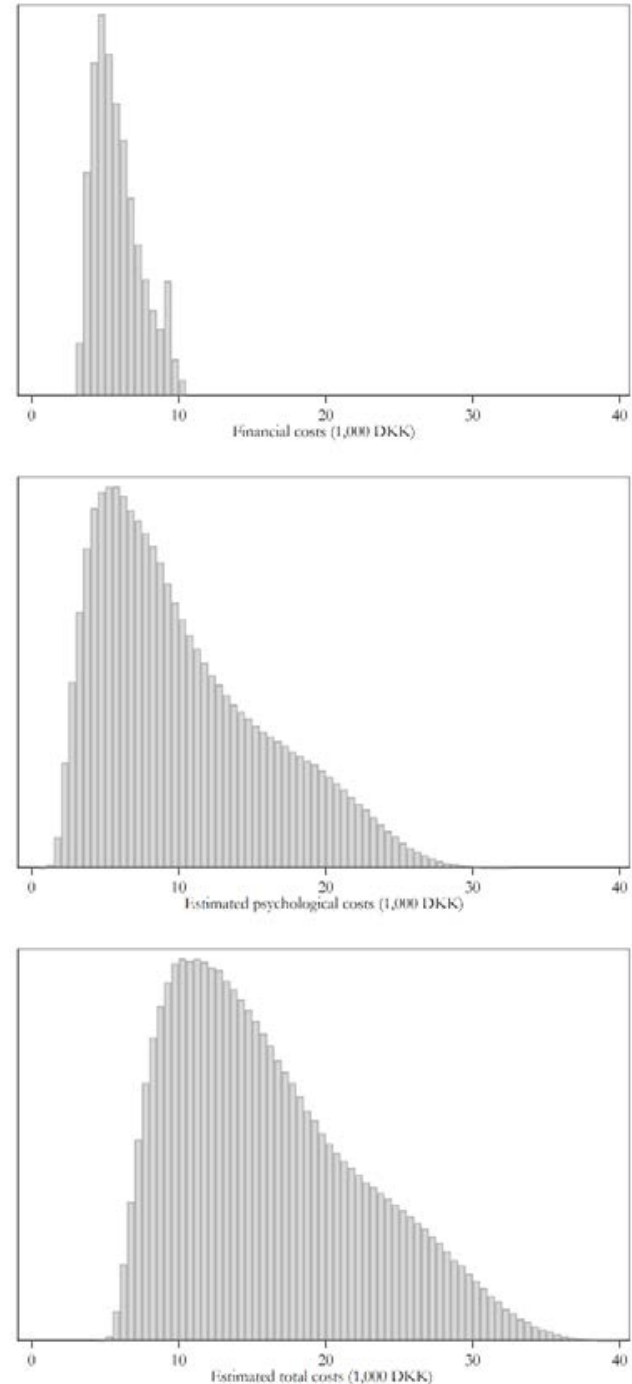
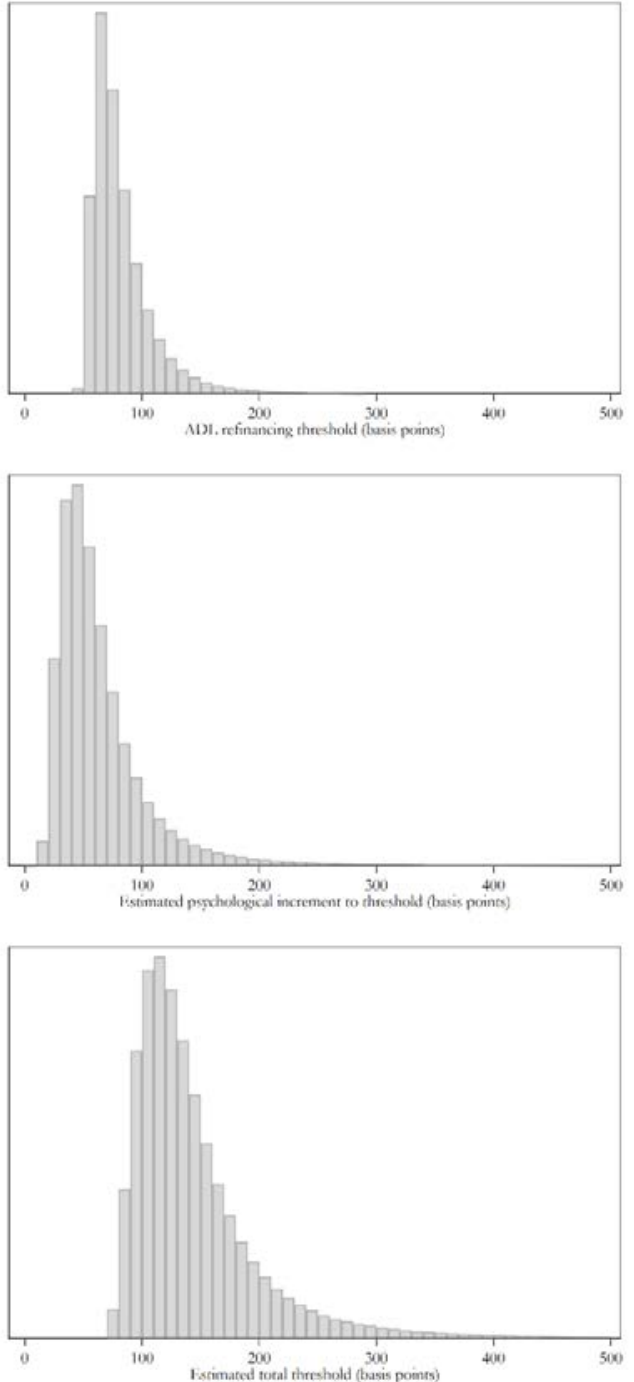


\section{Figure 8: Model Implied Time-Dependent Inaction Probability}

This figure shows the model implied probability of households being subject to time-dependent inaction, estimated using the model in Table 3. The top panel shows a histogram of the distribution of the estimated time-dependent inaction probability across households, computed using a representative quarter, i.e., inputting the average mortgage age effect and average current quarter time effect estimated in the data. The bottom panel shows a box plot of the model implied estimated time-dependent inaction probability for each quarter of our data, i.e., inputting the time effect and mortgage age effect for each quarter listed on the vertical axis.
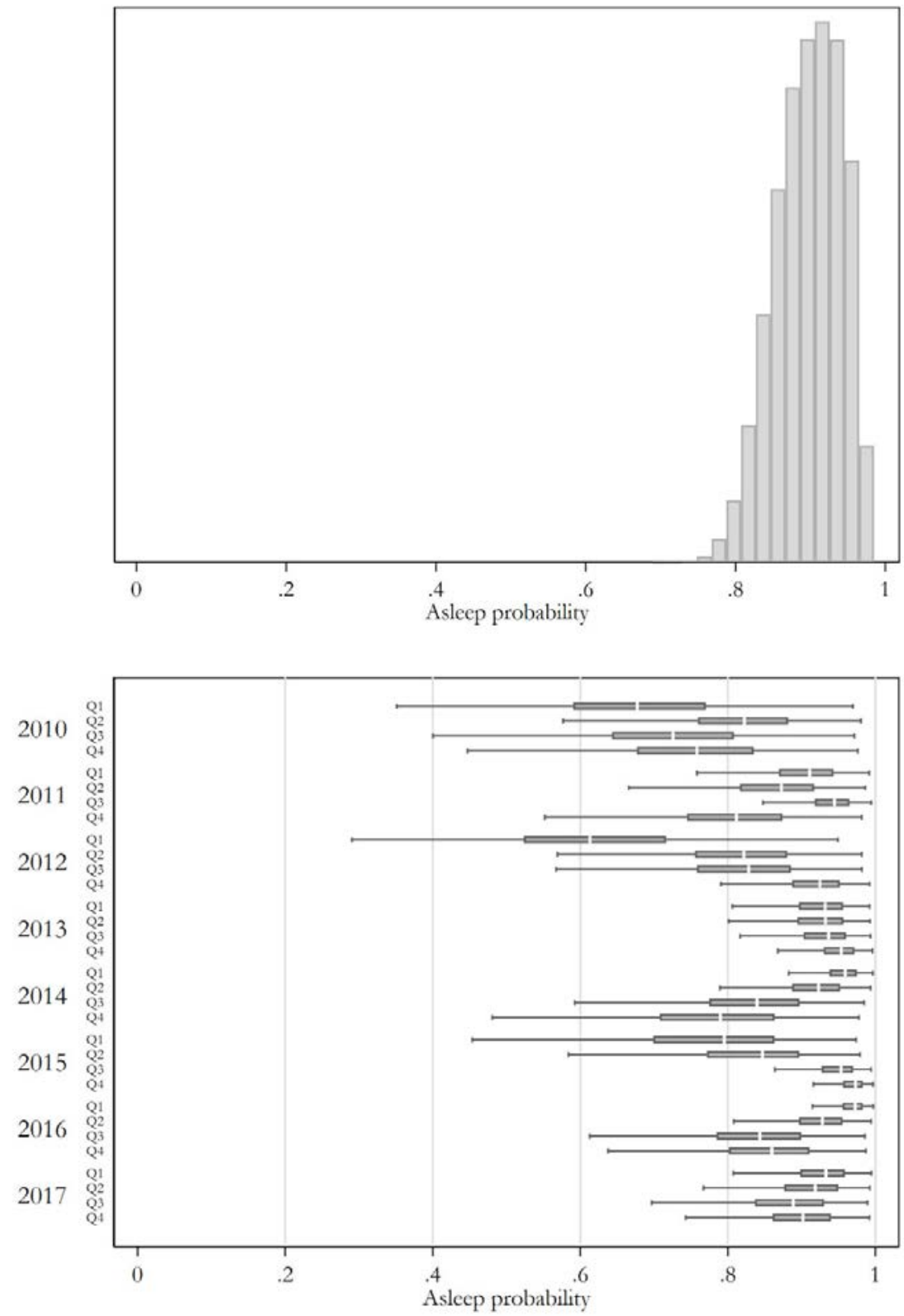


\section{Figure 9: Marginal Effects of Ranked Variables}

This figure shows the marginal change in the probability of being subject to time-dependent inaction, the estimated psychological costs of refinancing in 1,000 DKK, and the psychological cost increment to the interest-rate threshold to be surmounted to induce a household to refinance, all as functions of selected ranked variables: age, education, income, financial wealth, and housing wealth. To plot these marginal effects, we use the household-level fitted values of the baseline model presented in Table 3 .
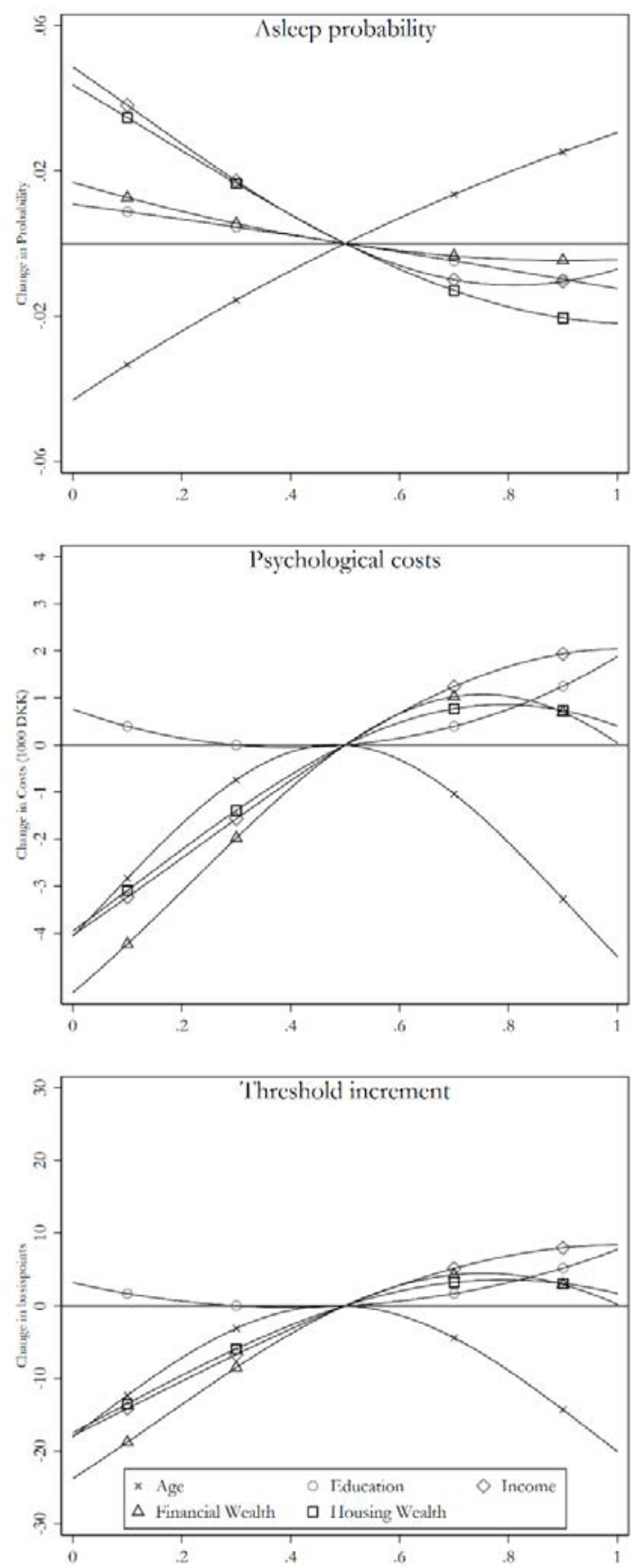


\section{Figure 10: Policy Experiments}

These figures consider policies to induce household refinancing alongside an interest rate cut in which $90 \%$ of Danish households have a refinancing incentive exceeding their ADL (2013) threshold: a policy in which mortgages automatically refinance when the interest rate saving exceeds the ADL threshold; a policy that "wakes up" households, cutting the asleep probability in half from its initial level; a policy that rebates all fixed fees incurred by households; a policy that combines "waking up" with the rebate; and a "do nothing policy" in which households refinance according to our baseline model. The top panel shows the fraction refinancing at each point in time, and the second (third) the fraction refinancing 8 quarters post-cut along the age (income) distribution.
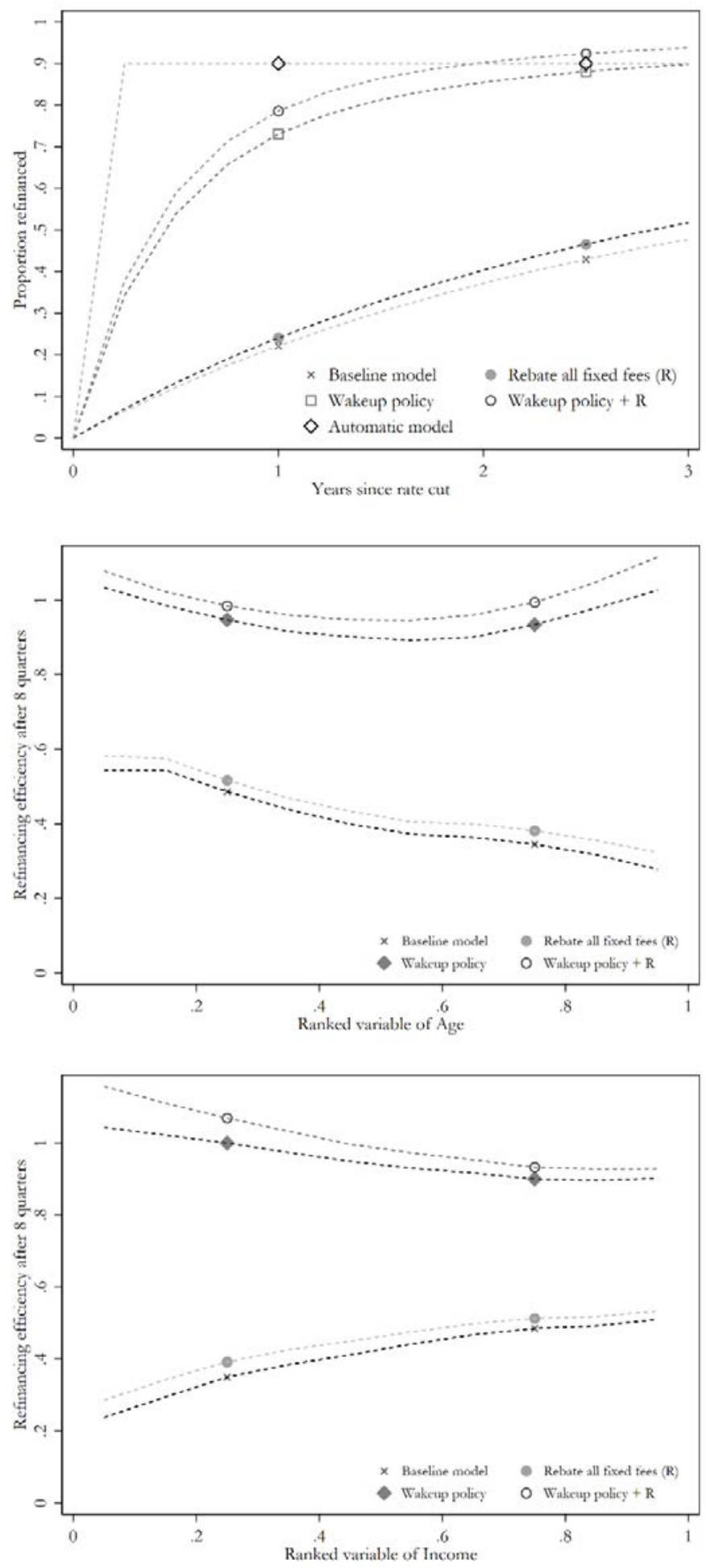